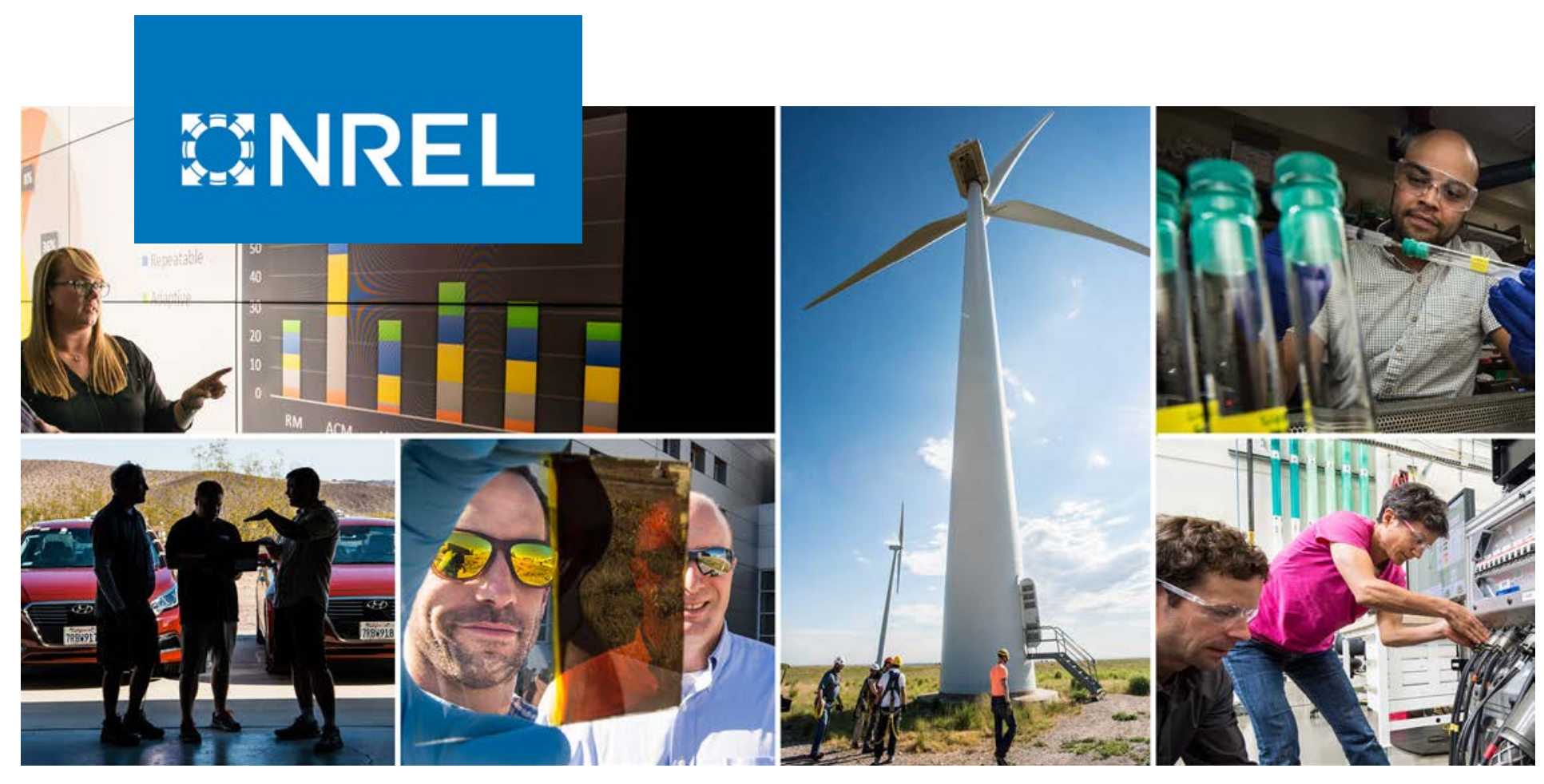

\title{
Least-Cost Pathways for India's Electric Power Sector
}

Amy Rose, llya Chernyakhovskiy, David Palchak, Sam Koebrich, and Mohit Joshi

National Renewable Energy Laboratory

NREL is a national laboratory of the U.S. Department of Energy Office of Energy Efficiency \& Renewable Energy

Operated by the Alliance for Sustainable Energy, LLC

This report is available at no cost from the National Renewable Energy Laboratory (NREL) at www.nrel.gov/publications.

\section{Technical Report}

NREL/TP-6A20-76153

May 2020 


\title{
GNREL
}

\section{Least-Cost Pathways for India's Electric Power Sector}

\author{
Amy Rose, llya Chernyakhovskiy, David Palchak, \\ Sam Koebrich, and Mohit Joshi
}

National Renewable Energy Laboratory

\section{Suggested Citation}

Rose, Amy, llya Chernyakhovskiy, David Palchak, Sam Koebrich, and Mohit Joshi. 2020. Least-Cost Pathways for India's Electric Power Sector. Golden, CO: National Renewable Energy Laboratory. NREL/TP-6A20-76153. https://www.nrel.gov/docs/fy20osti/76153.pdf.

NREL is a national laboratory of the U.S. Department of Energy Office of Energy Efficiency \& Renewable Energy Operated by the Alliance for Sustainable Energy, LLC

This report is available at no cost from the National Renewable Energy Laboratory (NREL) at www.nrel.gov/publications.

Contract No. DE-AC36-08GO28308
Technical Report NREL/TP-6A20-76153 May 2020

National Renewable Energy Laboratory 15013 Denver West Parkway Golden, CO 80401 303-275-3000 • www.nrel.gov 


\section{NOTICE}

This work was authored by the National Renewable Energy Laboratory, operated by Alliance for Sustainable Energy, LLC, for the U.S. Department of Energy (DOE) under Contract No. DE-AC36-08GO28308. Funding provided by U.S. Department of Energy Office of International Affairs, the Hewlett Foundation under Agreement 2017-5959, and the Children's Investment Fund Foundation under Agreement R-1807-02925. The views expressed herein do not necessarily represent the views of the DOE or the U.S. Government.

This report is available at no cost from the National Renewable Energy Laboratory (NREL) at www.nrel.gov/publications.

U.S. Department of Energy (DOE) reports produced after 1991 and a growing number of pre-1991 documents are available free via www.OSTI.gov.

Cover Photos by Dennis Schroeder: (clockwise, left to right) NREL 51934, NREL 45897, NREL 42160, NREL 45891, NREL 48097, NREL 46526.

NREL prints on paper that contains recycled content. 


\section{Acknowledgments}

The authors are greatly indebted to several individuals for their thoughtful feedback and guidance, including Elena Thomas-Kerr (U.S. Department of Energy), Priya Sreedharan (U.S. Agency for International Development), Ishan Sharan (Central Electricity Authority), Thomas

Spencer (The Energy and Resources Institute), Udetanshu (Climate Policy Initiative), and Pankaj Batra (Integrated Research and Action for Development). We also wish to thank the Regional Energy Deployment System (ReEDS) team at the National Renewable Energy Laboratory who supported this first adoption of the ReEDS model for a non-North American system, including Dan Steinberg, Maxwell Brown, Kelly Eurek, Will Frazier, and Wesley Cole. And thank you to Jaquelin Cochran, Maxwell Brown, Kapil Duwapi, and Mike Meshek for their reviews. Any errors and omissions are solely the responsibility of the authors.

This work was funded by the U.S. Department of Energy, the Hewlett Foundation, and the Children's Investment Fund Foundation. 


\section{List of Acronyms}

BA

BESS

CCGT

CEA

CT

DNI

DUPV

EPS

GAMS

GHI

GJ

GW

INR

$\mathrm{km}$

$\mathrm{kV}$

LCOE

LNG

MW

MWh

NREL

PV

RE

ReEDS

TWh

UPV

VRE

WHR balancing area

battery energy storage system

combined cycle gas turbine

Central Electricity Authority

combustion turbine

direct normal irradiance

distributed photovoltaic

Electric Power Survey

General Algebraic Modeling System

global horizontal irradiance

gigajoule

gigawatt

Indian rupee

kilometer

kilovolt

levelized cost of energy

liquified natural gas

megawatt

megawatt-hour

National Renewable Energy Laboratory

photovoltaic

renewable energy

Regional Energy Deployment System

terawatt-hour

utility photovoltaic

variable renewable energy

waste heat recovery 


\section{Executive Summary}

The Government of India has a target of deploying 175 gigawatts (GW) from renewable energy (RE) by 2022 and $40 \%$ of electricity capacity from RE by 2030 . Rapid changes in technology costs and performance could drive deployment of wind and solar capacity beyond these policy targets, and the Government of India has indicated its ambitions for 2030 could be higher than the targets. Meanwhile, increased deployment of variable renewable energy (VRE) raises new questions for power system planning regarding the optimal siting of generation capacity, tradeoffs between generation and transmission infrastructure, and system flexibility needs.

This study aims to evaluate least-cost pathways for India's electric power system over the period of 2017-2047. It builds on previous operational analysis of India's planned 2022 power system and state-of-the-art planning tools developed by the National Renewable Energy Laboratory. ${ }^{1}$ Uniquely, this study considers an expanded planning horizon and a range of scenarios not previously analyzed in national planning studies in India. The data collection and model design processes undertaken for the study provide a framework for recurring planning studies. Generally, the study finds anticipated changes in electricity demand and component costs could drive a significant shift in India's future electricity supply and how this system will be operated. Specifically, the study yields the following six findings.

India's electric power system is poised to shift from a thermal-based system to a renewable-based system.

Anticipated changes in component costs can drive a significant shift in the electricity supply with wind, solar photovoltaics (PV), and battery storage becoming increasingly competitive with thermal capacity. In the Base scenario, the share of installed capacity from coal decreases from $57 \%$ in 2017 to $19 \%$ in 2047, and the contribution from wind and solar increases from $17 \%$ to $58 \%$ over the same period. The share of generation from wind and solar reaches $54 \%$ by 2047 . In the Base scenario, investments in battery storage are economic in 2030 as a result of projected decreases in capital costs and increasing deployment of VRE resources, which are complemented by battery storage's ability to shift energy from high-RE periods to high-load periods.

Alternative scenarios whereby solar PV or battery costs decline faster than forecast reveal batteries could become economic as early as 2024 .

Investments in new capacity are increasingly driven by coincidence of VRE and demand rather than annual peak demand alone.

In a future system with high penetrations of RE, capacity additions are driven by the coincidence of demand and RE generation rather than peak demand alone (Figure ES-1). This study finds the system could have surplus capacity during the peak demand months of July through September because this period corresponds to periods with high wind speeds and more available wind generation to meet peak demand. By contrast, new capacity is needed to meet demand during the

\footnotetext{
${ }^{1}$ The model — the Regional Energy Deployment System (ReEDS)—is available at https://www.nrel.gov/analysis/reeds/.
} 
moderate demand months of October and November, when output from wind plants falls more than $75 \%$ nationally compared to August and September.

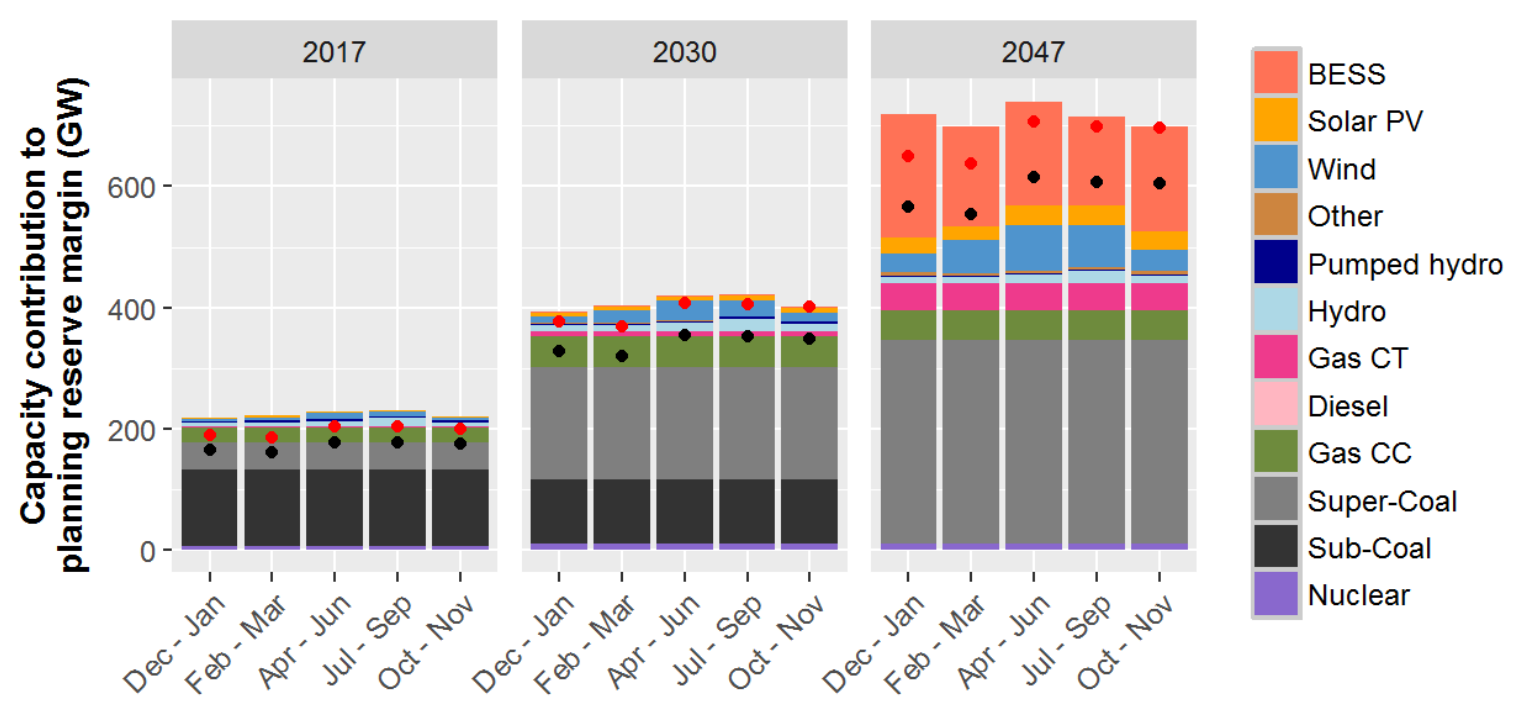

Figure ES-1 Change in capacity that is used to meet the planning reserve margin, Base scenario

The black dot indicates peak national demand and the red dot is the planning reserve margin requirement. BESS = battery energy storage system, CC = combined cycle, $\mathrm{CT}=$ combustion turbine, Sub-Coal = subcritical coal, and Super-Coal = supercritical coal.

\section{Battery storage plays a key role in enabling high penetrations of renewable energy.}

With battery storage, excess RE generated during low-demand periods can be stored and dispatched during high-demand hours when it is most needed. This is particularly important for solar PV, which is less available or unavailable during evening peak demand periods. This increases the economics of VRE resources and reduces the need for conventional peaking technologies, such as gas combustion turbines. By 2047, VRE resources account for 58\% of installed capacity and $54 \%$ of energy supplied with no curtailment. The share of VRE generation could increase more if battery costs decline faster than anticipated. An alternative scenario assuming capital costs for batteries decline at twice the rate forecast in the Base scenario finds VRE could provide $66 \%$ of annual energy.

\section{Differences in regional concentration of coal generation have implications for transmission investments and emissions.}

As increasing shares of location-dependent VRE resources are deployed, new interstate transmission capacity is needed to send otherwise-curtailed power to regions without strong VRE resources. In the Base scenario, investments in new transmission enable Madhya Pradesh to serve as a central corridor through which excess VRE generation is transmitted from the Western Region to the Northern and Eastern Regions (Figure 1).

Though total carbon emissions increase over the planning periods, as the amount of total electricity demand increases significantly, the emissions intensity decreases $47 \%$ from 0.76 metric tonnes of carbon dioxide per megawatt-hour in 2017 to 0.4 in 2047 . However, carbon emissions become increasingly concentrated in a few states. By 2047, 99\% of carbon emissions 
from electricity generation are produced in eight states, primarily in the Eastern Region, where coal remains cost-competitive with other technologies. The potential redistribution and concentration of emissions from the power sector may lead to emerging air quality concerns.

Reducing the capital cost of wind has a larger impact on VRE penetration than reducing the capital cost of solar PV or battery storage.

In the lowest wind cost scenario - in which capital cost declines $40 \%$ by 2047 relative to the Base scenario - the penetration of VRE in the generation mix reaches $72 \%$ (Figure ES- 2 ). This exceeds the penetration levels achieved in scenarios when the cost of battery storage or solar PV are reduced by an even greater 50\%. Unlike the other technology cost scenarios, reducing wind costs increases investments in gas combustion turbine capacity in the later years of the planning horizon to provide peaking capacity during October and November, when wind output is low.

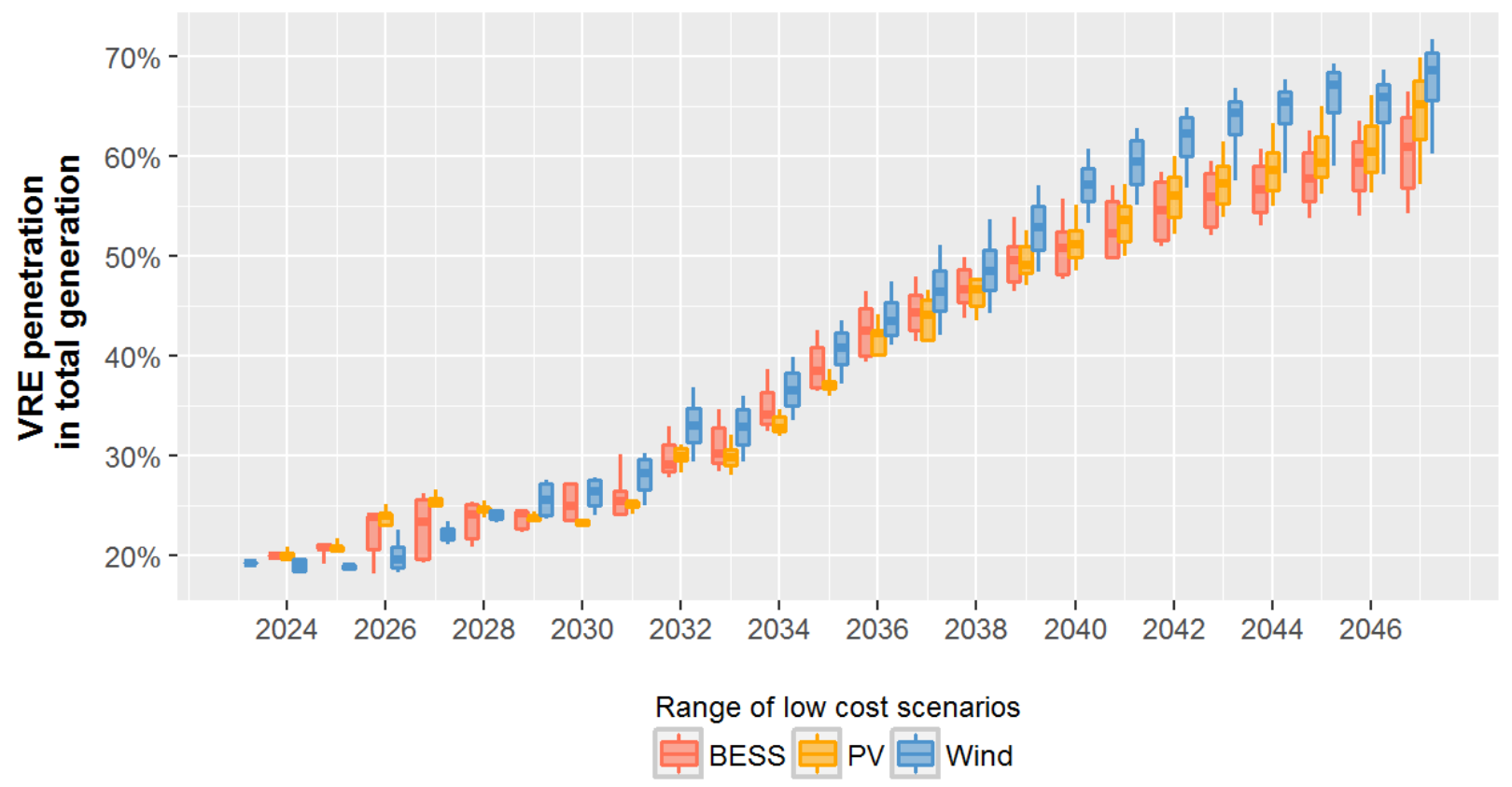

Figure ES-2 Range of VRE penetration in total generation in each model year in the BESS, solar

Boxes represent divisions into 25 th percent quartiles. The middle line is the median.

Investment in gas capacity for electricity production may depend on cost competitiveness rather than fuel availability.

Increasing the amount of gas available for electricity production has no significant impact on the capacity or generation mix by 2047 , as determined from a scenario that significantly increases fuel availability throughout the planning horizon. In fact, over $80 \%$ of new gas fuel available for the power sector remains unused. This suggests the high cost of gas plant operations relative to other technologies may constrain the expansion of gas generation in India more than fuel availability. 


\section{Table of Contents}

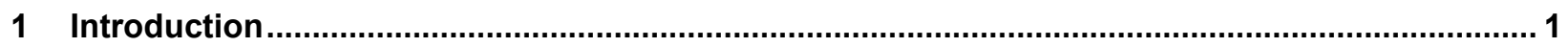

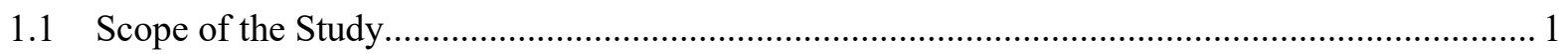

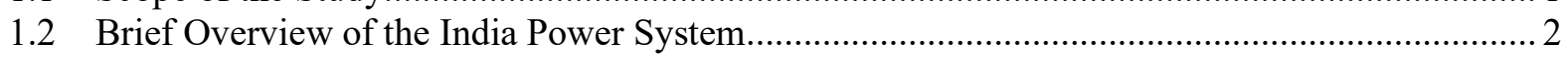

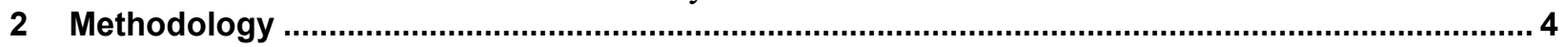

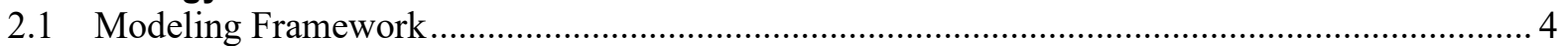

2.2 Model Development and Study Scenarios ........................................................................ 4

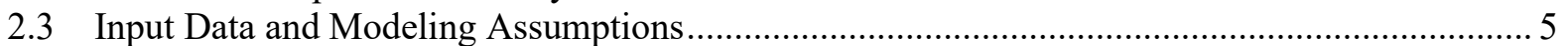

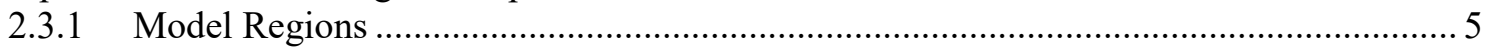

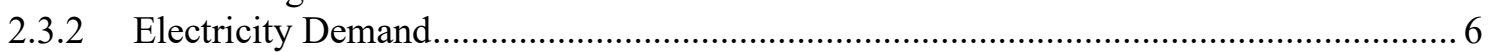

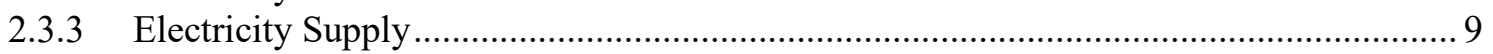

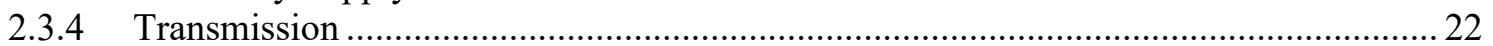

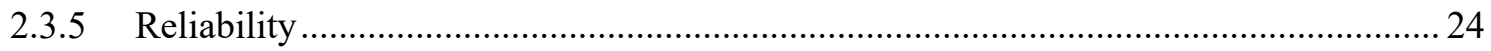

2.4 Data Limitations and Areas for Model Improvement ................................................ 25

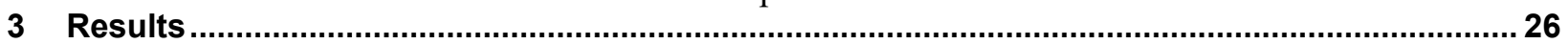

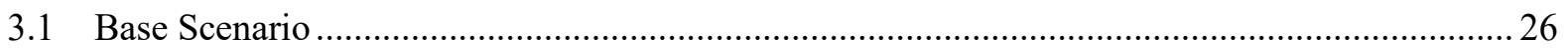

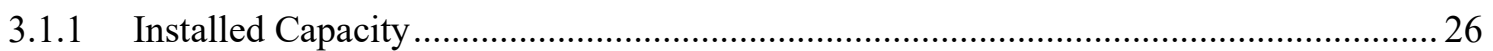

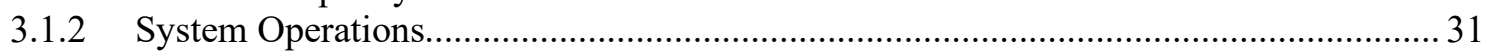

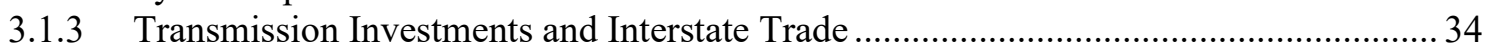

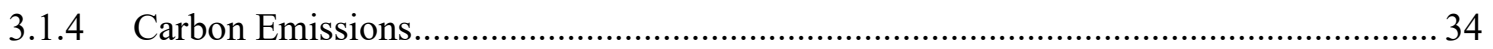

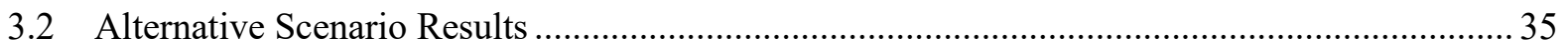

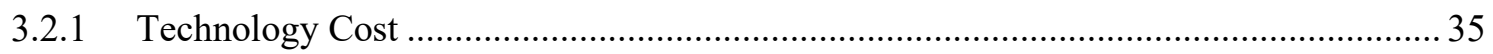

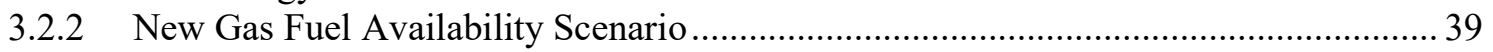

3.2.3 Improved Coal Flexibility Scenario ........................................................................ 40

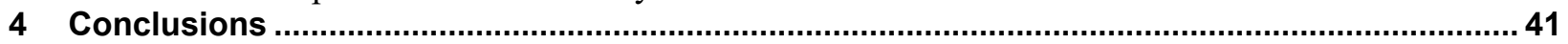

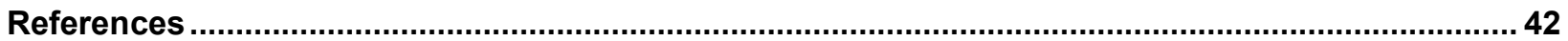




\section{List of Figures}

Figure ES-1 Change in capacity that is used to meet the planning reserve margin, Base scenario .............vi Figure ES-2 Range of VRE penetration in total generation in each model year in the BESS, solar PV, and

wind technology cost scenarios........................................................................................ vii

Figure 1. The five operating regions of the India electricity grid (Palchak et al. 2017) ........................... 3

Figure 2. Regions, balancing areas and resource regions in India ..................................................... 6

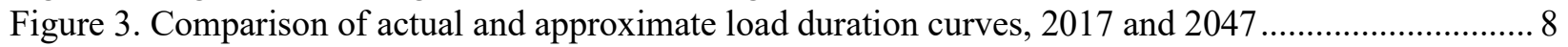

Figure 4. Patterns of approximation errors in potential (a) wind and (b) solar generation........................ 8

Figure 5. Summary of exogenously assigned capacity additions and retirements over the modeling period

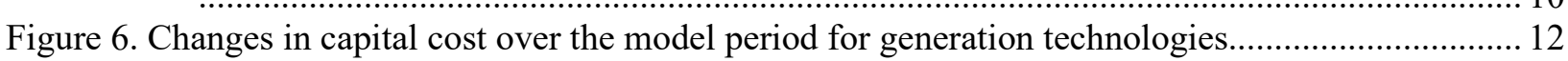

Figure 7. Change in capital costs in the alternative cost scenarios for BESS, solar PV, and wind ........... 13

Figure 8. Process to create the renewable energy supply curves ........................................................... 15

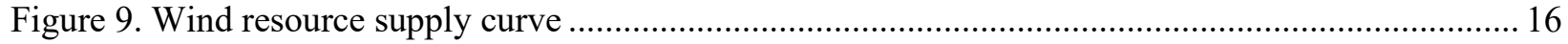

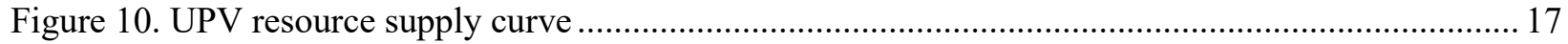

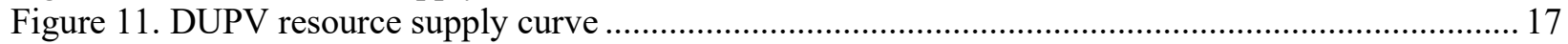

Figure 12. State-wise transport charge (INR/MWh) for coal delivered by rail ....................................... 19

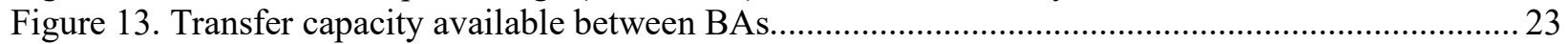

Figure 14. Total installed capacity, 2017-2047 in the Base scenario ......................................................26

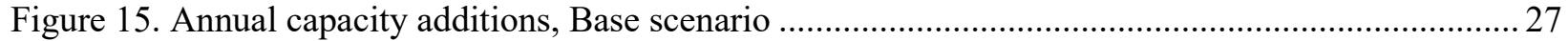

Figure 16. Change in capacity that is used to meet the planning reserve margin, Base scenario ............... 28

Figure 17. Change in installed capacity by region, Base scenario ..........................................................2 29

Figure 18. Location of (a) Gas CC, (b) Gas CT, and (c) Supercritical-coal in 2047, Base scenario .......... 30

Figure 19. Location of (a) Wind, (b) UPV, and (c) DUPV capacity in 2047, Base scenario ..................... 30

Figure 20. Absolute (a) and relative (b) annual generation mix for 2017-2047, Base scenario................. 31

Figure 21. Time-slice generation for the 2022 and 2047 model years in the Base scenario...................... 33

Figure 22. Total interstate (a) transmission capacity investments and (b) power flow in 2047,

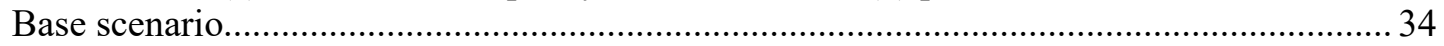

Figure 23. Carbon emissions intensity from electricity production by state, 2017 and $2047 \ldots \ldots \ldots \ldots \ldots \ldots . . . . .35$

Figure 24. Range of VRE penetration in total generation in each model year in the BESS, solar PV, and

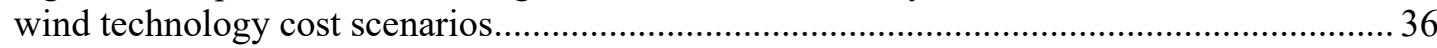

Figure 25. Total capacity installed through 2047 in the Base, Lowest Solar Cost, Lowest Battery Cost,

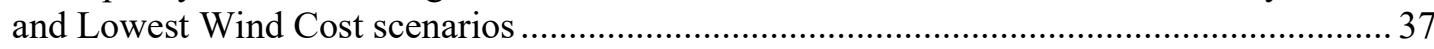

Figure 26. Comparison of 2047 time-slice generation for the Base, Low Battery Cost (BESS-50), Low Solar Cost (PV-50) and Low Wind Cost (Wind-40) scenarios ............................................. 38

Figure 27. Transmission capacity investments by 2047 in the Base and Low Wind Cost scenarios.......... 39 


\section{List of Tables}

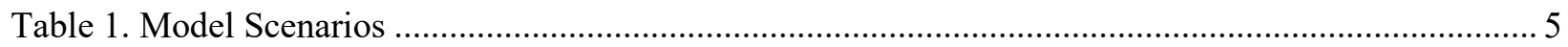

Table 2. Mapping of Hourly Electricity Demand into 35 Time-Slices .................................................... 7

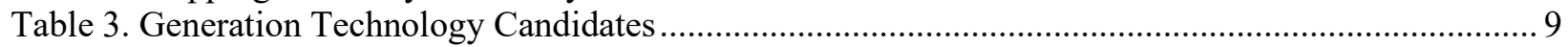

Table 4. Summary of Installed Capacity (GW) by Technology for 2017 ............................................ 10

Table 5. 2017 Capital Cost and Plant Lifetime Assumptions for Generation Technologies ...................... 11

Table 6. State-Wise Absolute Growth Limits on Installed Capacity for Select Technologies (MW) ........ 14

Table 7. Summary of Wind and Solar Resource Classes.................................................................... 16

Table 8. Technology Heat Rate Inputs........................................................................................... 19

Table 9. Technology Operating Parameters Assumed Constant Across All Balancing Areas and Model

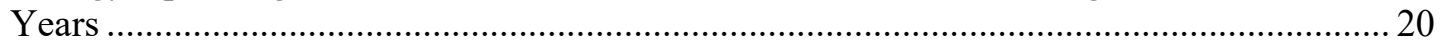

Table 10. Fuel Supply Limits on Gas for the Base and New Gas Scenarios ......................................... 22

Table 11. Capital Costs for Select Transmission Voltages ..................................................................... 23

Table 12. Input Assumptions for Operating Reserve Costs and Capabilities ..........................................25

Table 13. Evolution of Installed Capacity by Technology, Base Scenario............................................... 28

Table 14. Evolution of Generation Mix (Percentage of Total) by Technology, Base Scenario ................. 32

Table 15. VRE Penetration in Annual Generation and Average Fleet Load Factors for

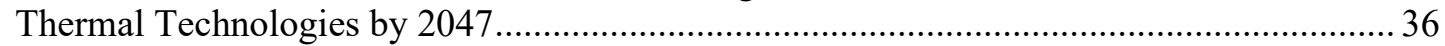

\section{List of Text Boxes}

Text Box 1. How well do time-slices approximate load and RE resources? ......................................... 8

Text Box 2. Approximation of operational aspects of VRE Technologies............................................... 21 


\section{Introduction}

Visionary government targets combined with rapid changes in technology costs and performance have the potential to drastically change electricity supply in India. The Government of India has a target of deploying 175 gigawatts $(\mathrm{GW})$ from wind, solar, biomass, and small hydropower by 2022 and $40 \%$ of electricity capacity from renewable energy (RE) by 2030 (UNFCCC 2015). Also, recent announcements have indicated more-ambitious RE targets for 2030 (Press Trust of India 2019). Falling technology costs would likely help achieve these targets and possibly drive further deployment of wind and solar capacity beyond the targets. In recent years, annual growth rates of wind and solar in India averaged 30\%, with solar alone achieving an annual growth rate of $82 \%$ in 2016 (MNRE 2018).

Increased deployment of variable renewable energy (VRE) raises new questions for system planners regarding the optimal siting of generation capacity, tradeoffs between generation and transmission investments, and system flexibility needs. Power system infrastructure is expensive and long-lived; it is therefore important to evaluate planning decisions in the future in which those assets will operate. The objective of this study is to develop a framework for evaluating least-cost pathways for India's electric power system over the period of 2017-2047. Long-term planning studies such as this one are relevant for a range of power sector stakeholders, including policymakers, utilities, project developers, consumer groups, and financing institutions to ensure the sector has an enabling policy, regulatory, and technical environment to achieve its goals.

This study is enabled through state-of-the-art modeling tool developed by the National Renewable Energy Laboratory (NREL) with support from the U.S. Department of Energy, the Hewlett Foundation, and the Children's Investment Fund Foundation. Our modeling work, which we report here, considers an expanded planning horizon and range of scenarios that have not been previously analyzed in national planning studies for India. And the model structure developed for this study can be applied to other systems to effectively characterize VRE in longterm planning decisions.

This report begins with a description of the methodology used for the study in Section 2. It is followed by a discussion of the results in Section 3. Section 4 concludes with a summary of key takeaways and future work.

\subsection{Scope of the Study}

This study analyzes the investment and operational needs of India's generation and transmission systems to meet anticipated system requirements from 2017 to 2047 at least cost. These system requirements include demand for energy, firm capacity, and operating reserves, as well as policy and regulatory mandates. The primary analysis tool is NREL's Regional Energy Deployment System (ReEDS) model. ReEDS explicitly addresses challenges associated with grid integration of VRE technologies through detailed temporal and geospatial representation of VRE resources.

Though ReEDS can be used to address a broad range of planning questions, it does not cover the full spectrum of issues associated with power system planning. Specifically, the model does not feature: 
- Production cost modeling of chronological unit commitment decisions

- Optimal power flow of the bulk transmission system

- Contingency analysis

- Market structure and tariff design

- Noneconomic (e.g., behavioral, social, or institutional) factors that may impact investment and dispatch decisions.

The study provides insight into how the power sector may evolve and the key drivers behind this evolution by investigating the impact of different trends (e.g., technology costs, fuel costs, and policy targets) on generation and transmission capacity investments in India. The relevant trends and range of possible futures will continue to evolve, prompting the need for ongoing refinement of the underlying data inputs and model scenarios. The data collection and model design processes undertaken for the study provide a framework for recurring planning studies. This work represents the first application of ReEDS outside North America as part of an effort to strengthen institutional capacity within India.

\subsection{Brief Overview of the India Power System}

As of 2019, India has an installed generation capacity of $357 \mathrm{GW}$, with coal and RE sources accounting for $194 \mathrm{GW}(54 \%)$ and $78 \mathrm{GW}(22 \%)$, respectively, and peak demand of $181 \mathrm{GW}$ (CEA 2019a, 2018a). The country is demarcated into five operating regions as shown in Figure 1 (next page), with most of the electricity demand and generating capacity divided evenly between the Northern, Western, and Southern Regions.

India's peak demand is expected to increase from $181 \mathrm{GW}$ in $2018-2019$ and to $520 \mathrm{GW}$ in 2036-2037, prompting the need for investments in generation infrastructure (CEA 2018b). Government targets and favorable economics could lead to an increasing share of generation capacity met with VRE technologies. Because VRE resources are not uniformly distributed in form or location (see Section 2.3.3.2), this could shift the mix and regional distribution of electricity supply. 


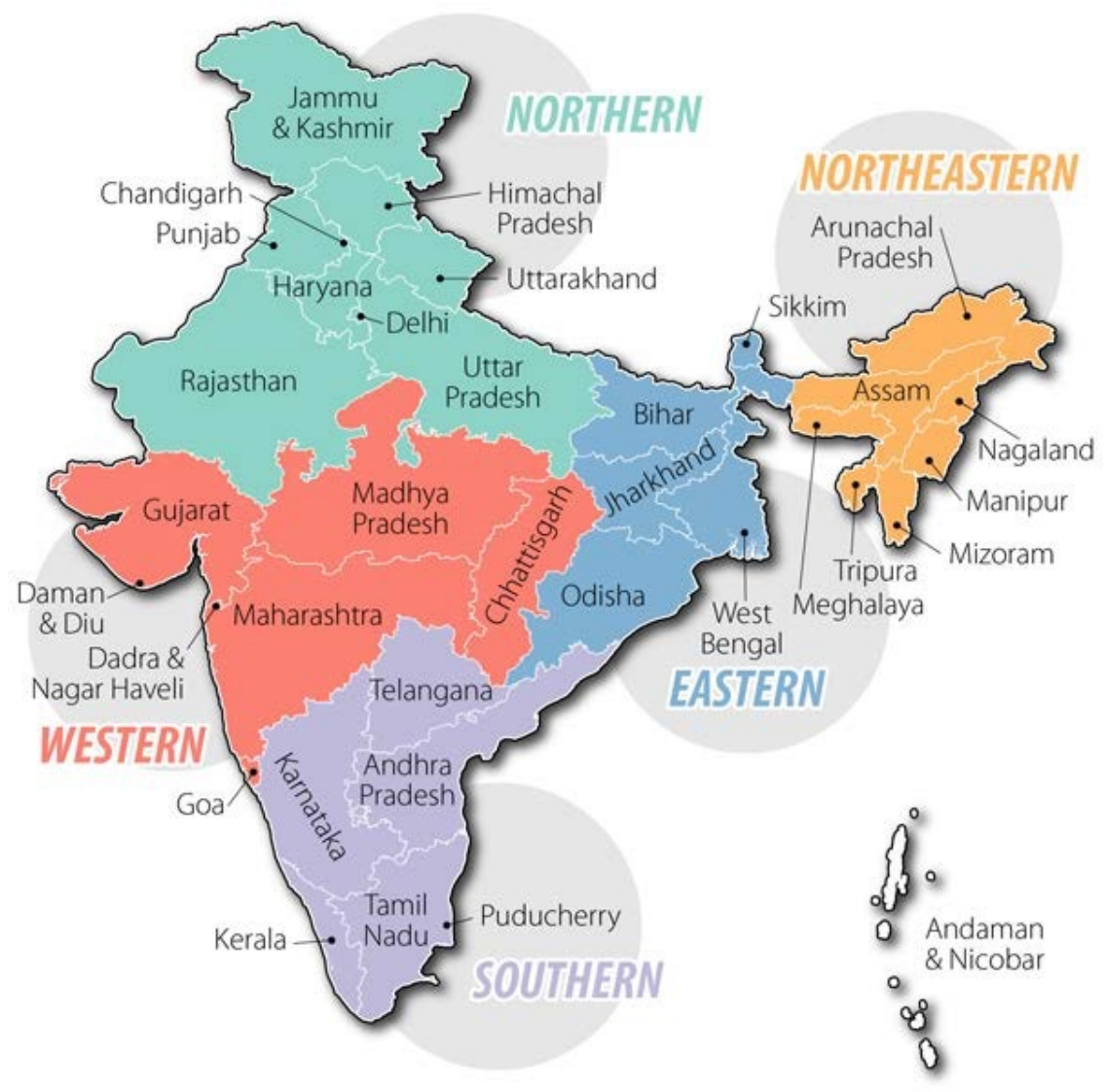

Figure 1. The five operating regions of the India electricity grid (Palchak et al. 2017) 


\section{Methodology}

The primary tool for this analysis is a capacity expansion model that identifies the least-cost mix of generation and transmission technologies required to meet future system needs. We use scenario analysis to address uncertainty in future technology costs, fuel availability, technology performance, and policies. This section describes the model development, study scenarios, data sources, and assumptions used in the study.

\subsection{Modeling Framework}

Capacity expansion models must balance the need for detailed representation of the electricity sector with computational complexity. Planning tools vary significantly in their treatment of operating constraints, energy prices, demand projections, as well as temporal and geographic resolution. For systems such as that of India, where VRE technologies may play an increasing role in the future generation mix, the appropriate tool should capture the diversity of candidate VRE technologies and their applications, the location-dependent quality of these resources, and inherent uncertainty and variability in wind and solar generation.

We selected the ReEDS ${ }^{2}$ capacity expansion model for this study for its rich assessment of technical, geographic, and operational aspects of VRE deployment. ReEDS is a linear optimization program that minimizes the net present value of investment and operating costs subject to several constraints. The major constraints include balancing electricity supply and demand, resource supply limits, planning and operating reserve constraints, transmission constraints, and policy targets. These constraints are met considering a broad portfolio of conventional generation, renewable generation, storage, and transmission technologies. More information on ReEDS can be found in Cohen et al. (2019). The ReEDS India model is implemented in the General Algebraic Modeling System (GAMS) programming language and is publicly available at https://www.nrel.gov/analysis/reeds/.

\subsection{Model Development and Study Scenarios}

The study considers six scenarios outlined in Table 1 (next page). The Base scenario is designed as a business-as-usual case, where trends in cost and operations remain relatively constant in the future. All subsequent scenarios change a single assumption from the Base. Details about the input values for each scenario are presented in Section 2.3.

For all scenarios, we assume perfect foresight; ${ }^{3}$ that is, investment and operating decisions are made assuming perfect knowledge about how technology costs and performance and electricity demand will change over time.

\footnotetext{
${ }^{2}$ For more information, see "Regional Energy Deployment System Mode," NREL, https://www.nrel.gov/analysis/reeds/.

${ }^{3}$ ReEDS also has the capability to run with limited or no foresight.
} 
Table 1. Model Scenarios

\begin{tabular}{|c|c|}
\hline Scenario & Description \\
\hline Base & $\begin{array}{l}\text { Capacity and demand growth are based on CEA National Electricity Plan } \\
\text { and } 19^{\text {th }} \text { Electric Power Survey (CEA 2018b) }\end{array}$ \\
\hline Low Solar Costs & $\begin{array}{l}\text { Solar photovoltaic (PV) capital costs decline more rapidly than in the Base } \\
\text { scenario }\end{array}$ \\
\hline Lower Wind Costs & Wind capital costs decline more rapidly than in the Base scenario \\
\hline Lower Battery Costs & $\begin{array}{l}\text { Battery energy storage system (BESS) capital costs decline more rapidly } \\
\text { than in the Base scenario }\end{array}$ \\
\hline New Gas & Gas availability for electricity generation increases in future years \\
\hline Coal Flex & The coal fleet achieves a minimum generation level of $40 \%$ \\
\hline
\end{tabular}

\subsection{Input Data and Modeling Assumptions}

The model database includes all existing generation and transmission infrastructure as well as a portfolio of planned and candidate investment options over the 2017-2047 period. The primary data sources include India's National Electricity Plan (CEA 2018c), the $19^{\text {th }}$ Electric Power Survey (EPS) (CEA 2018b), and the India power system database developed for the Greening the Grid India Study (Palchak et al. 2017). Additional information on data sources and assumptions for the ReEDS India model are presented in this section.

\subsubsection{Model Regions}

The model includes three levels of spatial resolution: regions, balancing areas (BAs), and resource regions. Regions include the five operating regions of India, namely, the Northern, Northeastern, Eastern, Southern, and Western Regions. Each region is composed of BAs representing states and union territories that are connected by the transmission network. We consider 34 total BAs. Finally, within each BA there are multiple resource regions designed to capture differences in RE resources at a higher level of granularity. There are 146 resource regions. Figure 2 shows how the country is divided into regions, BAs, and resource regions 


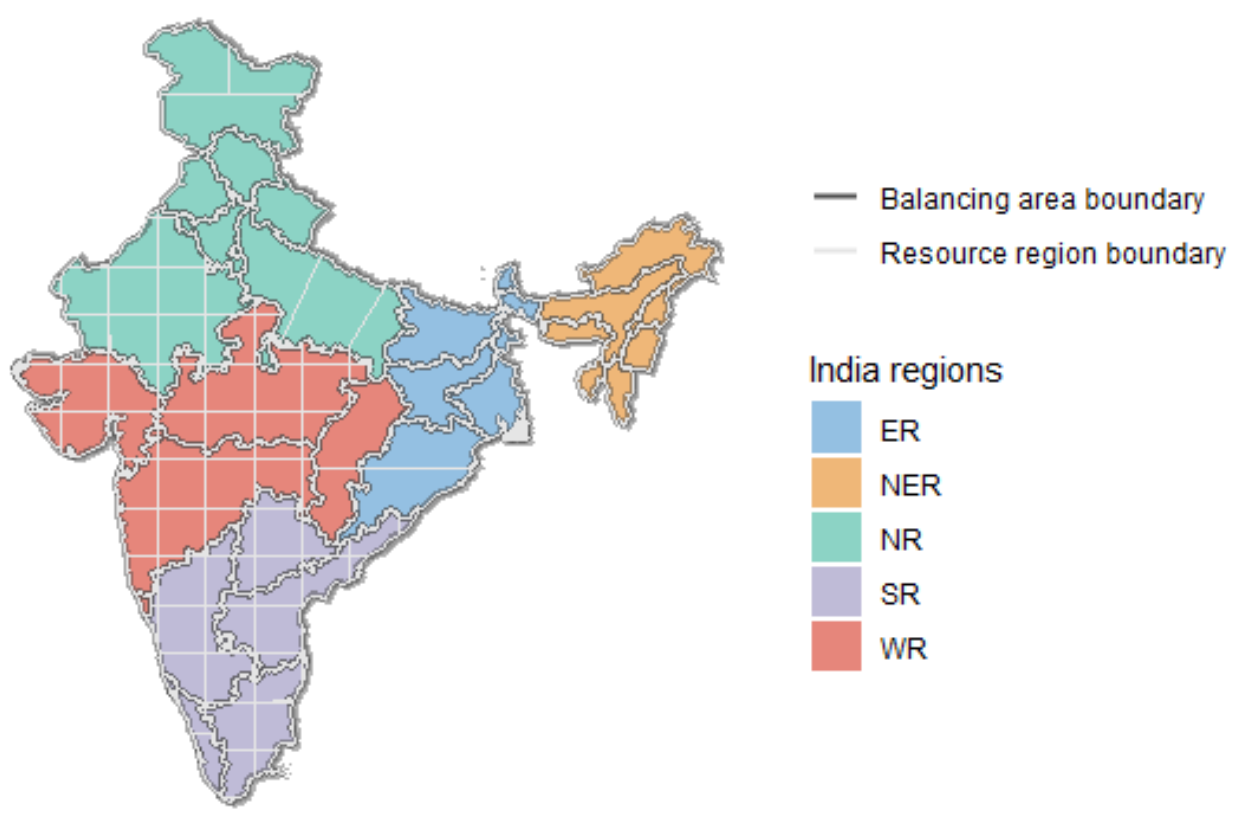

Figure 2. Regions, balancing areas and resource regions in India

\subsubsection{Electricity Demand}

India is expecting large changes in both the total amount of electricity demand and the daily patterns of demand over the model period. This section outlines the assumptions for demand growth and the approach to translate hourly demand data into a series of time-slices or representative hours.

\subsubsection{Time-Slices}

Annual demand is represented with 35 time-slices designed to capture changes in seasonal and daily demand patterns as well as wind and solar availability. The time-slices include five seasons (Winter, Spring, Summer, Rainy, and Autumn) with seven representative times of day per season (Night, Sunrise, Morning, Afternoon, Sunset, Evening, Peak). Table 2 (next page) shows how the demand in each hour is allocated to a particular time-slice. Each time-slice provides a representation of the typical electricity demand that occurs within the respective period (e.g., the Winter Night time-slice represents mean electricity demand between 12:00 a.m. and 6:00 a.m. from December through January).

Sunrise and sunset periods are determined based on 2022 solar generation profiles from Palchak et al. (2017). They represent the first and last three hours of the day when solar generation is available respectively. Peak period time-slices are not depicted in Table 2 because the peak hours vary by state. Periods of seasonal peak load for each state are determined based on the highest 40 state-wise demand hours.

After every hour of the year is allocated to one of the 35 time-slices, the time-slice load is calculated as the mean load from all hours assigned to that time-slice. We use hourly load data from Palchak et al. (2017) as the baseline for all demand calculations to align with the available weather data. We assess how well the time-slices approximate load and RE in Text Box 1. 
Table 2. Mapping of Hourly Electricity Demand into 35 Time-Slices

\begin{tabular}{|c|c|c|c|c|c|c|c|c|c|c|c|c|}
\hline & January & February & March & April & May & June & July & August & September & October & November & December \\
\hline & Winter & Spr & & & Summer & & & Rai & & & Imn & Winter \\
\hline 1 & \multirow{5}{*}{ Night } & \multirow{4}{*}{\multicolumn{2}{|c|}{ Night }} & \multirow{3}{*}{\multicolumn{3}{|c|}{ Night }} & \multirow{4}{*}{\multicolumn{3}{|c|}{ Night }} & \multirow{4}{*}{\multicolumn{2}{|c|}{ Night }} & \multirow{5}{*}{ Night } \\
\hline 2 & & & & & & & & & & & & \\
\hline 3 & & & & & & & & & & & & \\
\hline 4 & & & & \multirow{3}{*}{\multicolumn{3}{|c|}{ Sunrise }} & & & & & & \\
\hline 5 & & \multirow{3}{*}{\multicolumn{2}{|c|}{ Sunrise }} & & & & \multirow{3}{*}{\multicolumn{3}{|c|}{ Sunrise }} & \multirow{3}{*}{\multicolumn{2}{|c|}{ Sunrise }} & \\
\hline 6 & \multirow{3}{*}{ Sunrise } & & & & & & & & & & & \\
\hline 7 & & & & \multirow{5}{*}{\multicolumn{2}{|c|}{ Morning }} & & & & & & & Sunrise \\
\hline 8 & & \multirow{4}{*}{\multicolumn{2}{|c|}{ Morning }} & & & & \multirow{4}{*}{\multicolumn{3}{|c|}{ Morning }} & \multirow{4}{*}{\multicolumn{2}{|c|}{ Morning }} & \\
\hline 9 & \multirow{3}{*}{ Morning } & & & & & & & & & & & \\
\hline 10 & & & & & & & & & & & & Morning \\
\hline 11 & & & & & & & & & & & & \\
\hline 12 & \multirow{4}{*}{ Afternoon } & \multirow{4}{*}{\multicolumn{2}{|c|}{ Afternoon }} & \multirow{5}{*}{\multicolumn{2}{|c|}{ Afternoon }} & & \multirow{4}{*}{\multicolumn{3}{|c|}{ Afternoon }} & \multirow{4}{*}{\multicolumn{2}{|c|}{ Afternoon }} & \multirow{4}{*}{ Afternoon } \\
\hline 13 & & & & & & & & & & & & \\
\hline 14 & & & & & & & & & & & & \\
\hline 15 & & & & & & & & & & & & \\
\hline 16 & \multirow{3}{*}{ Sunset } & \multirow{3}{*}{\multicolumn{2}{|c|}{ Sunset }} & & & & \multirow{3}{*}{\multicolumn{3}{|c|}{ Sunset }} & \multirow{3}{*}{\multicolumn{2}{|c|}{ Sunset }} & \multirow{3}{*}{ Sunset } \\
\hline 17 & & & & \multirow{3}{*}{\multicolumn{3}{|c|}{ Sunset }} & & & & & & \\
\hline 18 & & & & & & & & & & & & \\
\hline 19 & \multirow{4}{*}{ Evening } & \multirow{4}{*}{\multicolumn{2}{|c|}{ Evening }} & & & & & & & & & \\
\hline 20 & & & & & & & & Even & & & ing & Evening \\
\hline 21 & & & & & Evening & & & & & & & \\
\hline 22 & & & & & & & & & & & & \\
\hline 23 & Nlight & & & & Night & & & $\mathrm{Nin}$ & & & & Night \\
\hline 24 & Ivigiil & & & & TNigmi & & & IVIg & & & & Ivigmil \\
\hline
\end{tabular}




\section{Text Box 1. How well do time-slices approximate load and RE resources?}

The model time-slices are designed to capture the major seasonal and diurnal trends in load and wind and solar resources needed for resource adequacy planning while maintaining a manageable number of decision variables. We validated the time-slices against hourly data to identify potential approximation errors. Figure 3 compares load duration curves for actual hourly and approximate (time-slice) load.
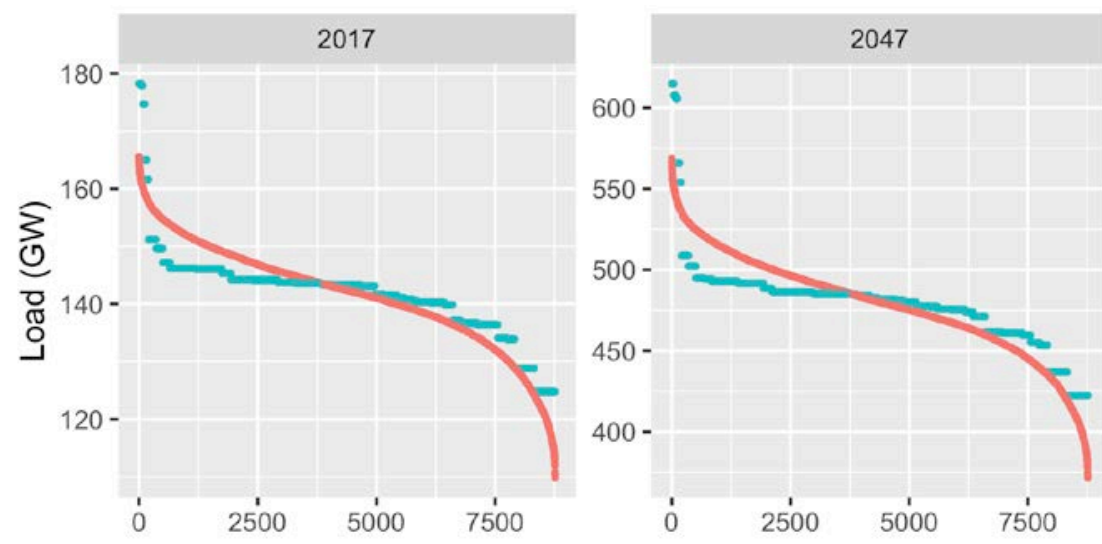

variable

- Actual

- Approximate

Figure 3. Comparison of actual and approximate load duration curves, 2017 and 2047

The time-slice approximation tends to overestimate periods with both very high load and very low load. System planners concerned with resource adequacy are most concerned about high-load periods. In both 2017 and 2047, the time-slice approximation overestimates peak load by $8 \%$, which is equivalent to $13 \mathrm{GW}$ and $46 \mathrm{GW}$ respectively. The actual peak demand tends to be lower than the time-slice approximation because, within the same season and part of the day (e.g., Summer Evening), states may experience peak demand on different days or different hours. The normalized root mean square error between the actual and approximate load is $14 \%$.

For RE resources, the time-slice approximation underestimates periods of both very high wind and very high solar availability, which may result in an underestimate of RE curtailment. For both wind and solar, the normalized root mean square error is $10 \%$. For wind, the time-slice approximation tends to underestimate wind resources during the high wind months of June and July (Figure 4). Approximation errors for solar follow a daily pattern where the time slices overestimate solar resources during the morning and early evening hours and underestimate solar resources during the middle of the day (Figure 4).

a

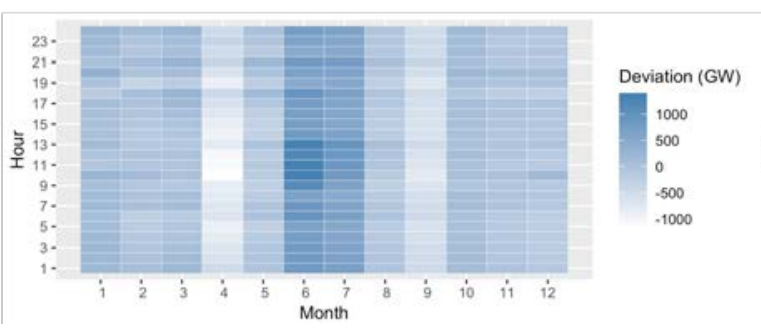

b

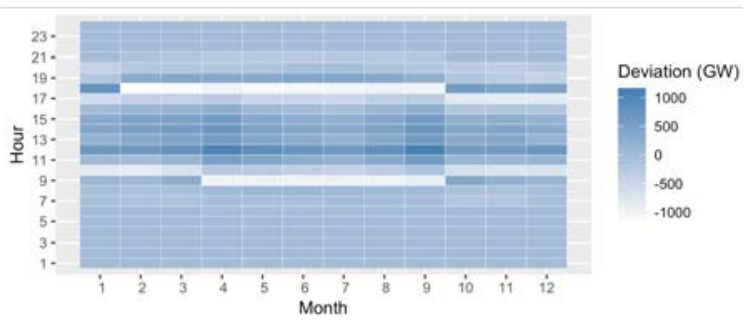

Figure 4. Patterns of approximation errors in potential (a) wind and (b) solar generation

Values $<0$ denote overestimate; values $>0$ denote underestimate. 


\subsubsection{Electricity Demand Forecast}

To capture anticipated growth in electricity demand, we create state-wise hourly demand profiles for each year over the 2017-2047 planning period. These are later reduced into 35 representative time-slices based on the classification described in Section 2.3.2.1.

Growth in annual and peak demand for each state and year is based on the $19^{\text {th }}$ EPS, which covers the periods of 2016-2017 to 2036-2037. After 2026, the forecasts are in five-year intervals. We assume linear growth in annual and peak demand over these five-year periods. For 2037-2047, we assume the same rate of demand growth as the previous five years. Total load growth for India averages 4.2\% and reaches 4,190 terawatt-hours (TWh) of total energy and $569 \mathrm{GW}$ of peak demand by the end of the analysis period. At the state level, different forecast rates of growth between annual and peak demand drive changes in the load shape over time, which results in flatter load profiles in some states or shifting of peak demand to daytime hours in others.

\subsubsection{Electricity Supply}

The generation fleet is represented by several different technology types, each with its own techno-economic parameters. Table 3 summarizes the generation technologies considered in the model.

Table 3. Generation Technology Candidates

\begin{tabular}{lll}
\hline Conventional & Renewable & Storage (duration) \\
\hline Combined-cycle gas turbine (CCGT) Gas & Distributed PV (DUPV) & BESS (4-hour) \\
CCGT liquified natural gas (LNG) & Hydro pondage & Hydro pumped (12-hour) \\
Combustion turbine (CT) gas & Hydro run-of-river & \\
Cogeneration bagasse & Hydro storage (reservoir) & \\
Diesel & Onshore wind & \\
Nuclear & Utility PV (UPV) & \\
Subcritical coal & \\
Subcritical lignite & & \\
Supercritical coal & & \\
Waste heat recovery (WHR) & \\
\hline
\end{tabular}

${ }^{a}$ BESSs are considered grid-connected, grid-scale energy storage assets that are independently operated and can be independently sited or co-located with RE or conventional power plants. Potential cost savings from shared equipment in tightly-coupled RE and BESS projects are not considered in this study.

${ }^{b}$ Offshore wind is not included as a candidate because of insufficient data about resource and technical potential.

Simplifications are made in the representation of generation units to maintain a tractable optimization problem. Here we aggregate all units of the same technology within a BA, with the exception of wind and solar, which are aggregated by resource region. To capture differences in cost and performance of units of the same technology, we cluster units into "performance bins" based on their techno-economic parameters. Information on this clustering approach is presented in Section 2.3.3.3. 


\subsubsection{Existing and Committed Generation Capacity}

Input data for exogenously defined capacity include existing capacity, planned capacity additions, and planned retirements sourced from Palchak et al. (2017), CEA (2018c), and consultations with the Central Electricity Authority (CEA) of India. Table 4 summarizes the installed capacity assumed to exist in 2017, and Figure 5 shows the planned additions and retirements through 2047.

Table 4. Summary of Installed Capacity (GW) by Technology for 2017

\begin{tabular}{|c|c|c|c|c|c|c|c|c|c|c|c|}
\hline \multicolumn{2}{|c|}{ VRE } & \multicolumn{2}{|c|}{ Hydro } & \multirow[t]{2}{*}{ Nuclear } & \multicolumn{6}{|c|}{ Thermal } & \multirow[t]{2}{*}{ Total } \\
\hline Wind & $\begin{array}{l}\text { Solar } \\
\text { PV }\end{array}$ & $\begin{array}{l}\text { Pumped } \\
\text { hydro }\end{array}$ & Hydro & & $\begin{array}{l}\text { Super- } \\
\text { coal }\end{array}$ & $\begin{array}{l}\text { Sub- } \\
\text { coal }\end{array}$ & $\begin{array}{l}\text { Gas } \\
\text { CC }\end{array}$ & $\begin{array}{l}\text { Gas } \\
\text { CT }\end{array}$ & Diesel & Other & \\
\hline 28.5 & 21.3 & 3.2 & 42.7 & 6.9 & 45.8 & 125.3 & 23.9 & 0.4 & 0.8 & 0.5 & 299.3 \\
\hline
\end{tabular}
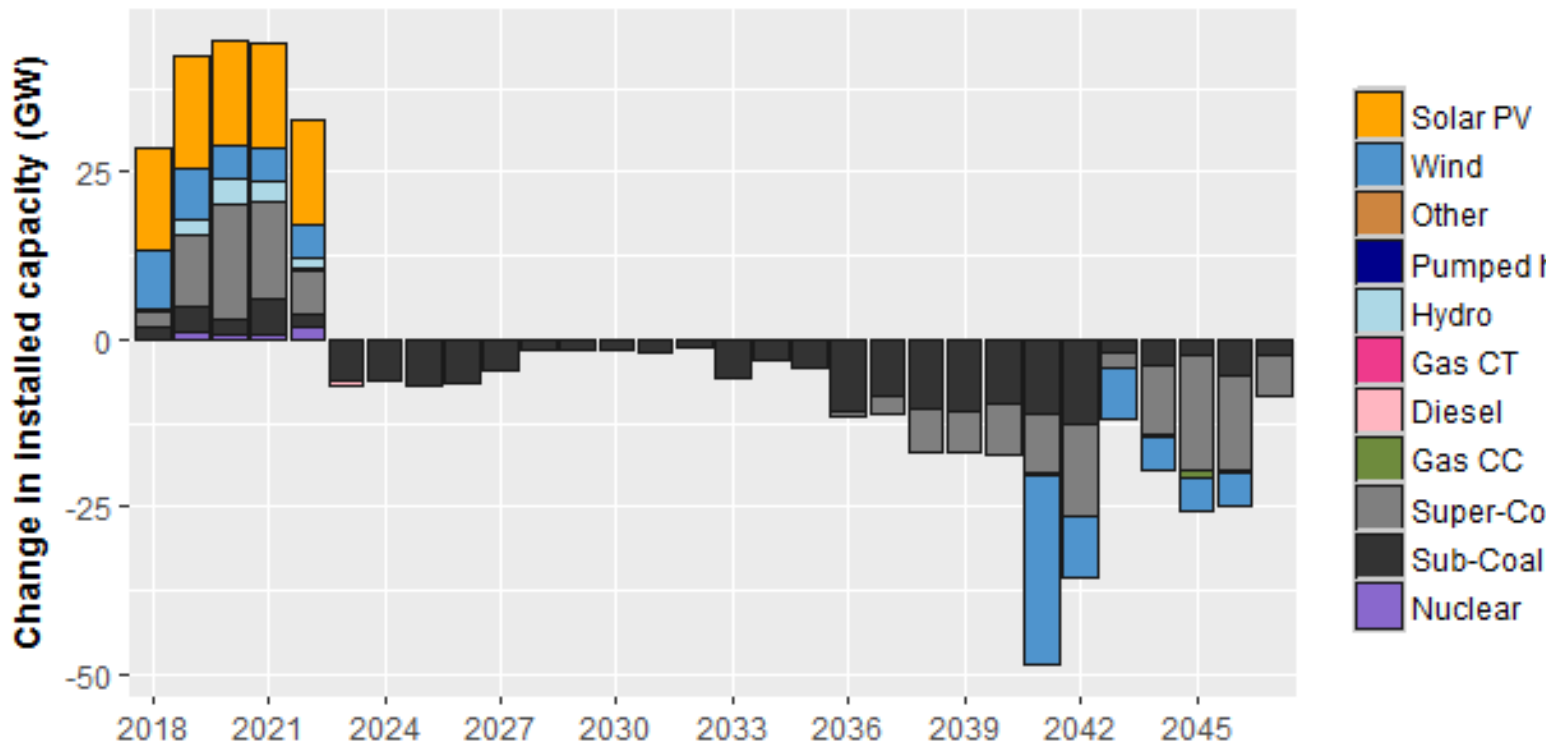

Pumped hydro

Hydro

Gas CT

Diesel

Gas CC

Super-Coal

Sub-Coal

Nuclear

Figure 5. Summary of exogenously assigned capacity additions and retirements over the modeling period

In Figure 5, retirements include prescribed retirements as well as age-based retirements based on the plant's assumed economic lifetime and commissioning date. A plant's economic lifetime is determined by the technology, which is provided in Section 2.3.3.2.

\subsubsection{Technology Options for Expansion}

Future electricity supply needs can be met by any of the thermal, nuclear, or renewables-based technologies presented in Table 3. The optimal mix of technologies is based on several factors, including the cost of development, operation and maintenance costs, policy targets, and resource availability. The next two subsections present the investment parameters and constraints for capacity investments. 


\section{Investment Parameters}

Table 5 lists capital cost and plant lifetime assumptions by technology. Unless otherwise stated, all capital cost assumptions are taken from CEA (2018c). The plant lifetime is the maximum operating age of the plant after which it must be retired or refurbished.

Table 5. 2017 Capital Cost and Plant Lifetime Assumptions for Generation Technologies

\begin{tabular}{lcc} 
Technology & $\begin{array}{c}\text { 2017 Capital Cost } \\
\text { (crore/MW) }^{\mathbf{b}}\end{array}$ & $\begin{array}{c}\text { Plant Lifetime } \\
\text { (years) }\end{array}$ \\
\hline BESS & $9.1^{\mathrm{c}}$ & 15 \\
CCGT gas & $4.7^{\mathrm{d}}$ & 55 \\
CCGT LNG & 4.7 & 55 \\
Cogeneration bagasse & 5.7 & 45 \\
Gas CT & $4.0^{\mathrm{d}}$ & 55 \\
Diesel & $4.0^{\mathrm{e}}$ & 55 \\
DUPV & $13.1^{\mathrm{f}}$ & 30 \\
Hydro pondage & 10.0 & 100 \\
Hydro pumped & 10.0 & 100 \\
Hydro run-of-river & 6.5 & 100 \\
Hydro storage & 10.0 & 100 \\
Nuclear & 10.2 & 100 \\
Subcritical coal & 6.5 & 25 \\
Subcritical lignite & 6.5 & 25 \\
Supercritical coal & 6.5 & 25 \\
UPV & 5.5 & 30 \\
WHR & $5.7^{\mathrm{g}}$ & 45 \\
Wind & 6.0 & 24 \\
\hline
\end{tabular}

a Capital costs in this report represent the all-in installation cost, including hard costs (i.e., equipment) and balance-of-system costs (i.e., labor, software, permitting, land acquisition, and other fees).

${ }^{b}$ A crore denotes 10 million rupees.

${ }^{c}$ Based on BNEF (2019)

d Based on NREL (2018) assumption that CC units are 17\% more expensive that CT units

e Based on CEA (2016b) because capital costs for gas plants were unavailable in CEA (2018c)

${ }^{f}$ BNEF (2017) value for commercial rooftop PV

g Based on capital cost for Cogeneration bagasse

For all technologies, both mature and emerging, there is a learning rate that results in reductions in capital costs over time as manufacturers and developers gain experience with the technology. We adopt the same learning rates used in NREL's 2018 Annual Technology Baseline "Mid" estimates. Figure 6 shows the anticipated changes in capital cost over the model period for each candidate technology. 


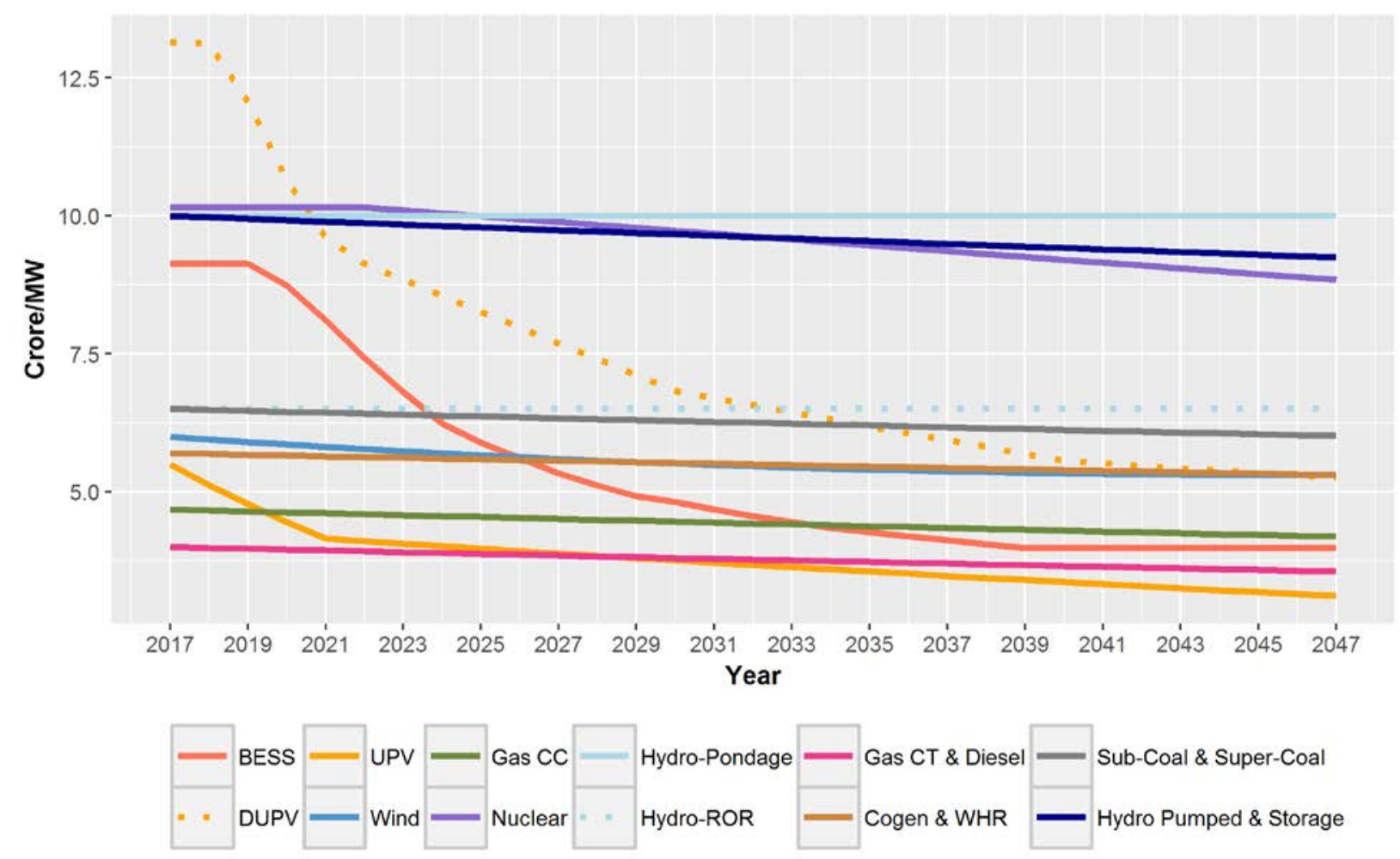

Figure 6. Changes in capital cost over the model period for generation technologies

The Lower Solar Costs, Lower Wind Costs, and Lower Battery Costs scenarios investigate different future trajectories for capital costs for solar PV, wind, and BESS technologies, respectively, by assuming capital costs decline more rapidly than in the Base scenario. For each technology, we include five sensitivities whereby the 2047 capital cost is $10 \%, 20 \%, 30 \%, 40 \%$, or $50 \%$ lower than projected in the Base scenario (Figure 7). 


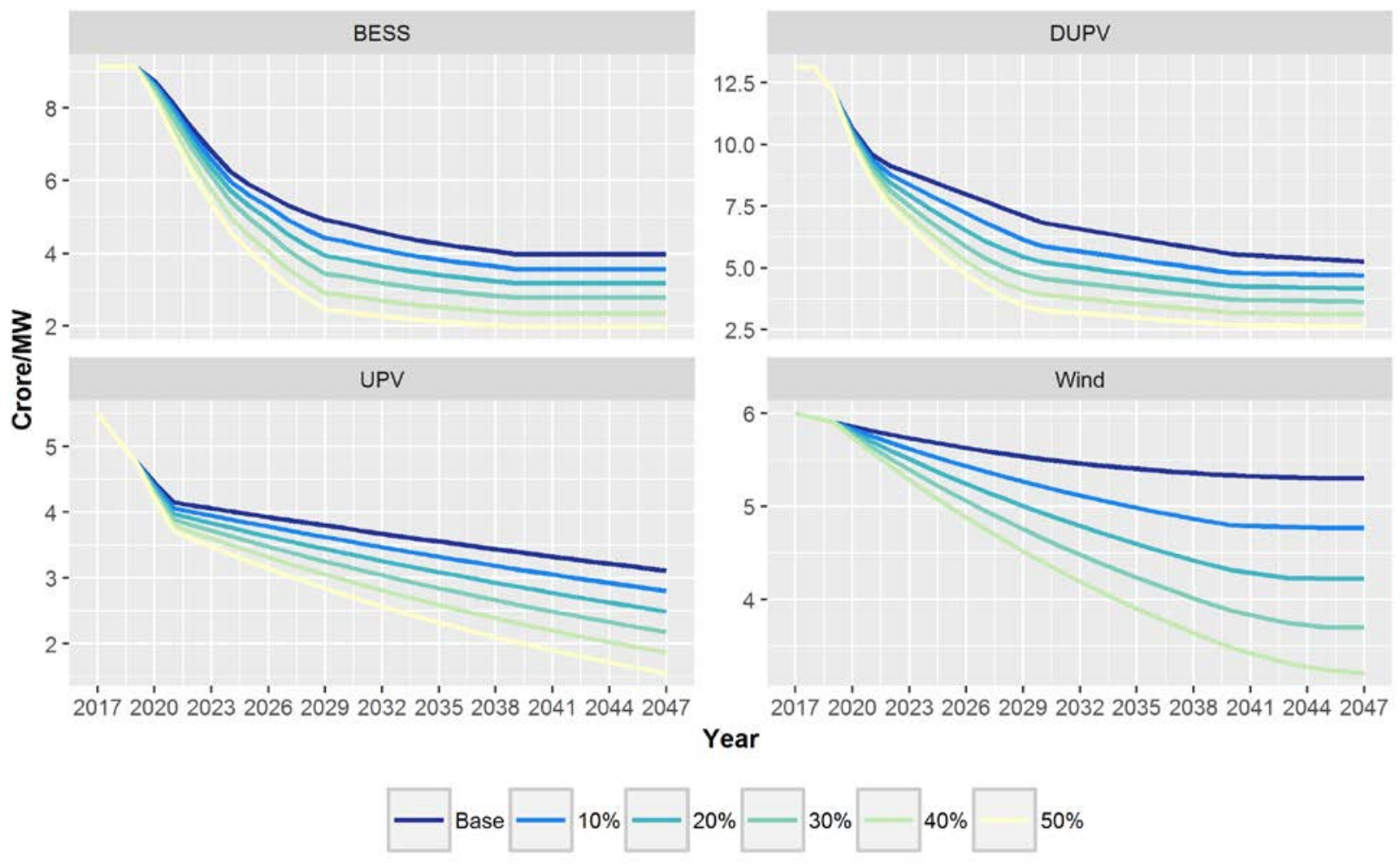

Figure 7. Change in capital costs in the alternative cost scenarios for BESS, solar PV, and wind

A $50 \%$ cost decline scenario for wind technologies is not included because this scenario is outside the range of potential cost futures projected in NREL's 2019 Annual Technology Baseline (NREL 2019).

\section{Investment Constraints}

The investment constraints represent policy, resource, or technical criteria that may influence investment outcomes. We impose three types of investment constraints on generation additions: (1) first year for endogenous capacity additions, (2) absolute growth limits, and (3) relative growth limits.

The first year for endogenous capacity additions is the initial year when new capacity can be built based on economic criteria. Before the first year, only prescribed additions can be added. For all technologies except wind and solar, we assume projects not already underway will not be complete by 2023. Therefore, these technologies cannot begin economic builds until 2023.

The absolute growth limit represents the state-wise capacity limits on hydro, biomass, and waste heat recovery (WHR) technologies based on their estimated potential (CEA 2018c; CEA 2018d). Table 6 contains the absolute growth limits for each state and technology type. 
Table 6. State-Wise Absolute Growth Limits on Installed Capacity for Select Technologies (MW)

\begin{tabular}{|c|c|c|c|c|c|c|}
\hline State & $\begin{array}{c}\text { Cogeneration } \\
\text { Bagasse }\end{array}$ & $\begin{array}{l}\text { Hydro } \\
\text { Pondage }\end{array}$ & $\begin{array}{l}\text { Hydro: } \\
\text { Pumped }\end{array}$ & $\begin{array}{l}\text { Hydro: Run } \\
\text { of River }\end{array}$ & $\begin{array}{l}\text { Hydro: } \\
\text { Storage }\end{array}$ & WHR \\
\hline Andhra Pradesh & 578 & 1,100 & 0 & 0 & 1,571 & 423 \\
\hline Arunachal Pradesh & 8 & 549 & 0 & 39,669 & 10,110 & 0 \\
\hline Assam & 212 & 25 & 0 & 237 & 418 & 38 \\
\hline Bihar & 619 & 0 & 0 & 70 & 0 & 373 \\
\hline Chandigarh & 0 & 0 & 0 & 0 & 0 & 0 \\
\hline Chhattisgarh & 236 & 0 & 0 & 489 & 1,753 & 24 \\
\hline Dadra and Nagar Haveli & 0 & 0 & 0 & 0 & 0 & 0 \\
\hline Daman Diu & 0 & 0 & 0 & 0 & 0 & 0 \\
\hline Delhi & 0 & 0 & 0 & 0 & 0 & 131 \\
\hline Goa & 26 & 0 & 0 & 0 & 55 & 0 \\
\hline Gujarat & 1,221 & 250 & 0 & 240 & 1,500 & 462 \\
\hline Haryana & 1,333 & 0 & 0 & 64 & 0 & 374 \\
\hline Himachal Pradesh & 142 & 6,718 & 0 & 10,559 & 1,543 & 2 \\
\hline Jammu and Kashmir & 43 & 1,796 & 0 & 12,305 & 45 & 0 \\
\hline Jharkhand & 90 & 143 & 468 & 8 & 135 & 10 \\
\hline Karnataka & 1,131 & 507 & 1,493 & 281 & 4,320 & 450 \\
\hline Kerala & 1,044 & 51 & 872 & 164 & 2,428 & 36 \\
\hline Madhya Pradesh & 1,364 & 765 & 0 & 553 & 1,550 & 78 \\
\hline Maharashtra & 1,887 & 285 & 284 & 214 & 2,987 & 1,537 \\
\hline Manipur & 13 & 0 & 0 & 933 & 851 & 2 \\
\hline Meghalaya & 11 & 20 & 0 & 1,903 & 471 & 2 \\
\hline Mizoram & 1 & 0 & 0 & 65 & 2,131 & 2 \\
\hline Nagaland & 10 & 0 & 0 & 808 & 766 & 0 \\
\hline Odisha & 246 & 115 & 434 & 83 & 2,368 & 22 \\
\hline Puducherry & 0 & 0 & 0 & 0 & 0 & 3 \\
\hline Punjab & 3,172 & 206 & 0 & 494 & 1,925 & 345 \\
\hline Rajasthan & 1,039 & 0 & 0 & 36 & 461 & 62 \\
\hline Sikkim & 2 & 732 & 0 & 2,161 & 1,393 & 0 \\
\hline Tamil Nadu & 1,070 & 602 & 400 & 660 & 520 & 601 \\
\hline Telangana & 0 & 186 & 1,606 & 0 & 582 & 0 \\
\hline Tripura & 3 & 0 & 0 & 15 & 0 & 2 \\
\hline Uttar Pradesh & 1,617 & 103 & 0 & 320 & 300 & 1,426 \\
\hline Uttarakhand & 24 & 1,423 & 1,000 & 13,246 & 2,506 & 5 \\
\hline West Bengal & 396 & 252 & 1,619 & 263 & 707 & 148 \\
\hline All India & 17,538 & 15,828 & 8,175 & 85,839 & 43,394 & 6,558 \\
\hline
\end{tabular}


Finally, we use relative growth and geographic diversity constraints to prevent unrealistic rates of capacity growth in any single year or location. All technologies except BESS are constrained with a 50\% year-over-year limit of growth relative to installed capacity in the previous year.

\section{Renewable Resource Supply Curves}

ReEDS uses supply curves for wind and solar to characterize the potential sites available for development and directly evaluate the investments of these generation sources. These supply curves are estimated from detailed weather data, geospatial constraints, and economic assumptions using the process presented in Figure 8.

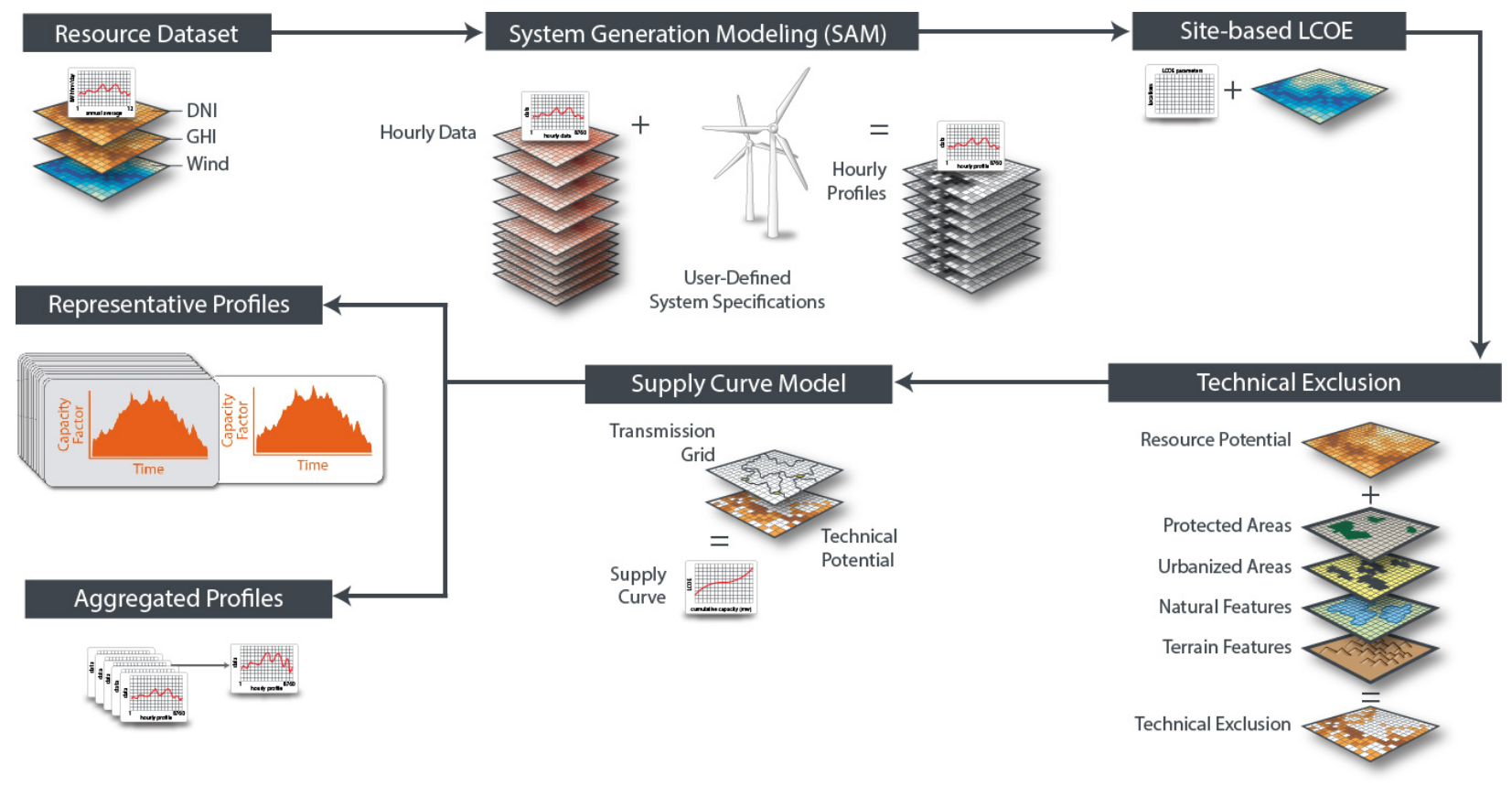

Figure 8. Process to create the renewable energy supply curves

Source: Maclaurin et al. 2019

$\mathrm{DNI}=$ direct normal irradiance, $\mathrm{GHI}=$ global horizontal irradiance;

$\mathrm{DNI}$ and $\mathrm{GHI}$ are measures of solar energy potential.

First, we input detailed spatiotemporal weather data and predefined system configurations for candidate technologies to create hourly generation profiles for each location and technology for the 2014 weather year. These are combined with financial assumptions about technology capital costs, fixed operating costs, and grid integration costs (i.e., transmission upgrades) to calculate site-based levelized cost of energy (LCOE). Land exclusion filters that are based on geospatial data on land characteristics, uses, and cover are applied to eliminate areas unavailable for development. After removing exclusion areas, a final technical potential for each gridded area is combined with geospatial information on the transmission network to create a resource supply curve based on total LCOE, which includes both site-based and transmission cost considerations. Finally, hourly profiles for each potential site are created to estimate generation, curtailment, and capacity credit for all wind and solar investments. 
UPV, DUPV, and wind technologies in each gridded cell are assigned to classes based on the quality of the resource (i.e., irradiance or wind speed) at a specific location. Solar has more resource classes (nine), representing the larger range of resource values in which solar plants can operate. Wind, by contrast, generally operates in a narrow range of wind speeds and has only three resource classes. Table 7 summarizes the resource classes for wind and solar.

Table 7. Summary of Wind and Solar Resource Classes

\begin{tabular}{rcr}
\hline Class & $\begin{array}{c}\text { Solar } \\
\text { (kWh/m2-day) }\end{array}$ & $\begin{array}{c}\text { Wind } \\
(\mathbf{m} / \mathbf{s})\end{array}$ \\
\hline 1 & $3.0-3.5$ & $>9$ \\
2 & $3.5-4.0$ & $>8-9$ \\
3 & $4.0-4.5$ & $\leq 8$ \\
4 & $4.5-5.0$ & - \\
5 & $5.0-5.5$ & - \\
6 & $5.5-6.0$ & - \\
7 & $6.0-6.5$ & - \\
8 & $6.5-7.0$ & - \\
9 & $7.0-7.5$ & - \\
\hline
\end{tabular}

Based on these classes, Figures 9-11 summarize the wind and solar supply curves for India. The inset shows the entire supply curve and the main plot shows a detailed view of the first $300 \mathrm{GW}$.

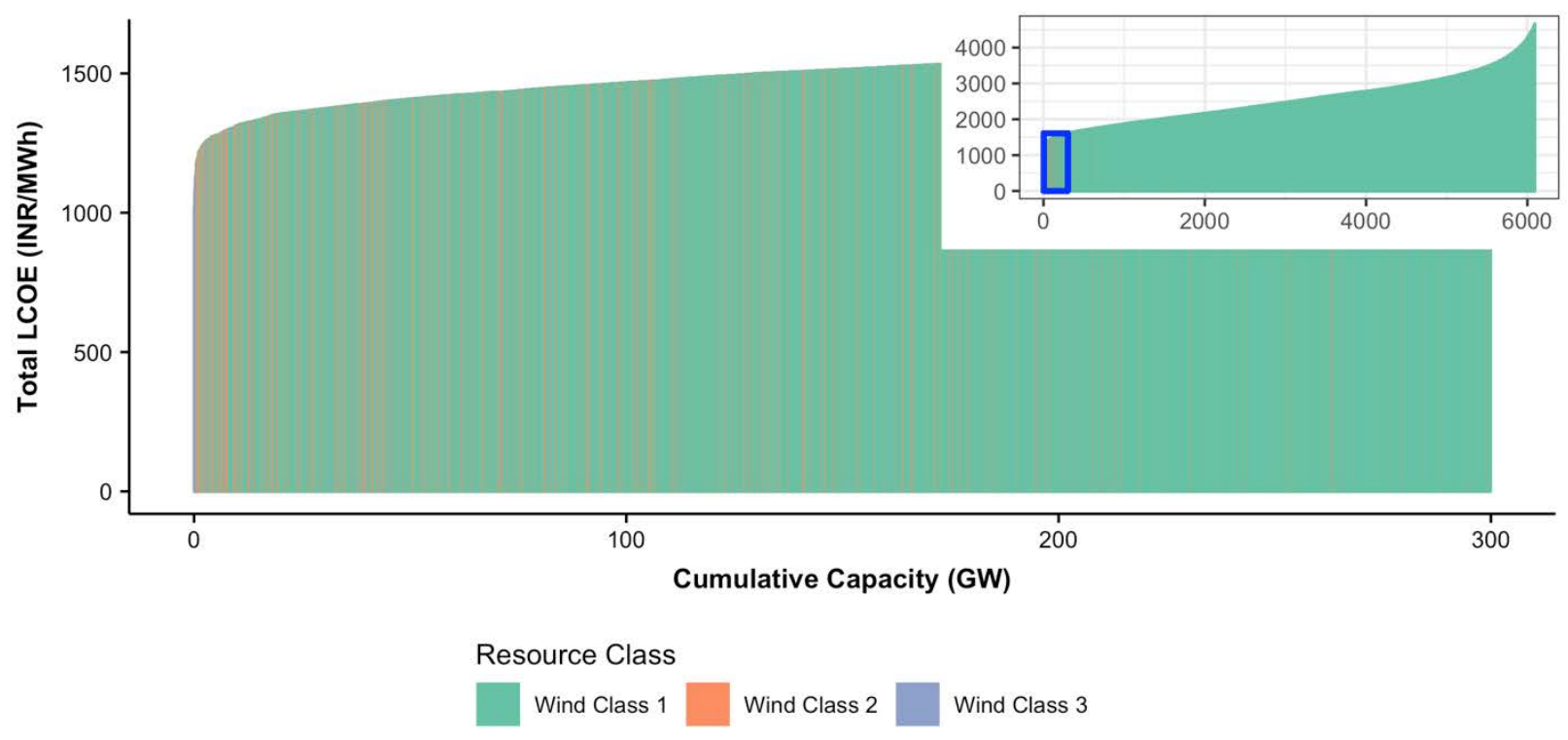

Figure 9. Wind resource supply curve 


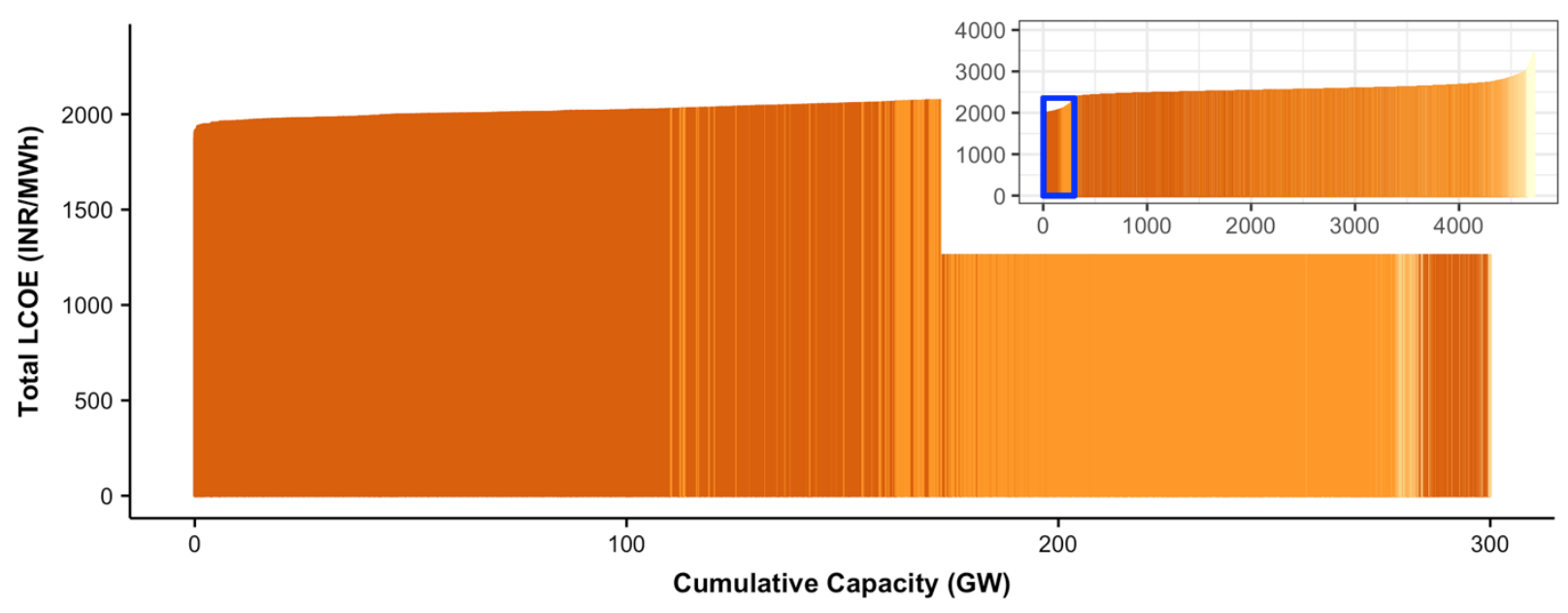

Resource Class

UPV Class 1

UPV Class $2 \quad$ UPV Class 3

UPV Class 4

UPV Class 5

UPV Class 6

UPV Class 7

Figure 10. UPV resource supply curve

Not all solar resource classes (i.e., Classes 8 and 9) are available in India.

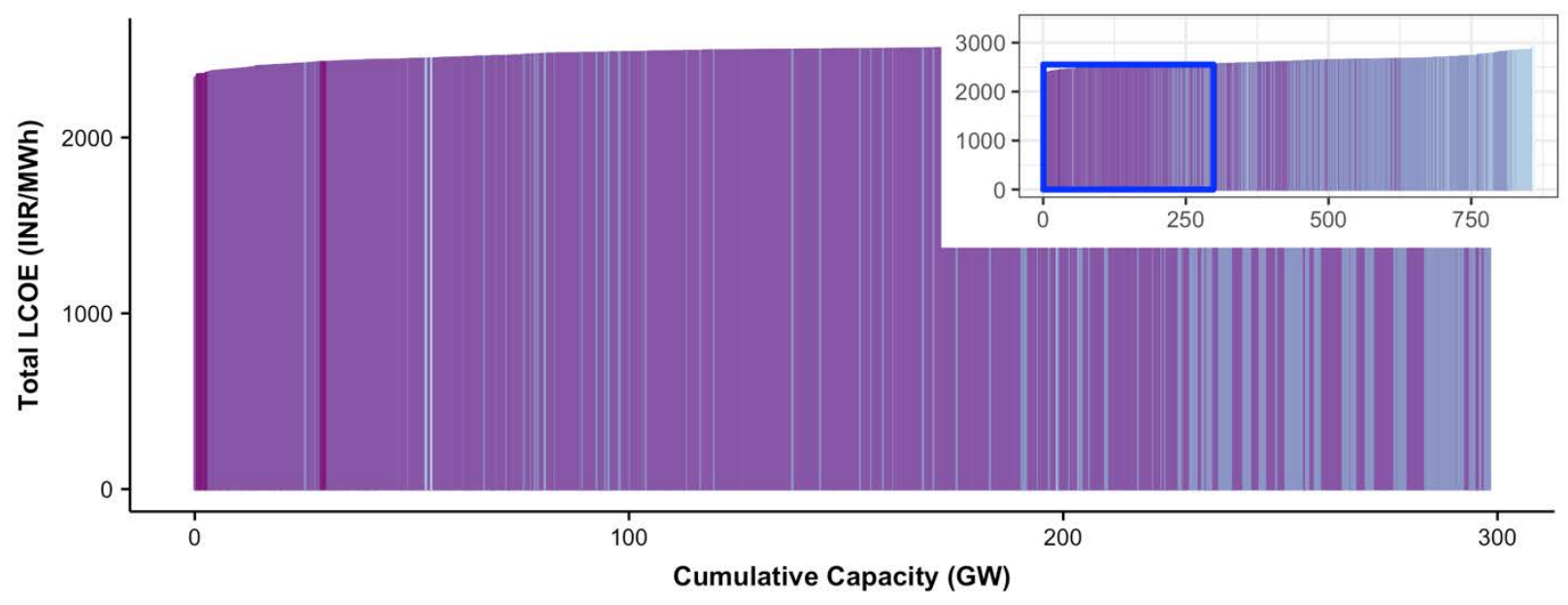

Resource Class

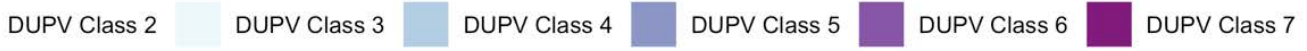

Figure 11. DUPV resource supply curve

Areas with stronger renewable resources (higher wind speeds or solar irradiance) tend to have lower LCOE values, meaning these areas are less expensive to develop. However, this is not always the case, as can be seen in Figures 9-11 where, for example, areas with strong solar resources (UPV Class 7) have higher LCOE values than areas with lower solar resources (UPV Class 5). This can occur if no transmission is available in the vicinity and the assumed cost for grid interconnection is high. This example demonstrates the value of including detailed geospatial data for both renewable resources and grid infrastructure to improve the estimated cost of developing a particular site. 
Using this information, each of India's 146 resource regions is assigned a maximum developable capacity (MW), interconnection cost (INR/MW), and capacity factor by time-slice and hour for every applicable resource class of wind, UPV, and DUPV.

\subsubsection{System Operations}

ReEDS uses a reduced form-dispatch where generation technologies, rather than individual units, are dispatched to meet requirements for operating reserves and electricity demand in each timeslice. This section presents the operational characteristics and constraints designed to capture the cost and performance characteristics of each technology type. Unless otherwise stated, all inputs are taken from Palchak et al. (2017).

\section{Operating Parameters}

Within the same region or type of technology, individual units can have different operating costs and performance. In addition, for many technologies, we can expect operating costs and plant efficiency to improve over time. We use the variable operation and maintenance cost parameter to capture differences in unit cost and performance for existing and planned units. Within each BA, we cluster individual units into "performance bins" or groups of units with similar costs. We stipulate that each bin must have at least five units and that the minimum deviation in average variable cost between bins must exceed 200 Indian rupees (INR) per megawatt-hour (MWh). ${ }^{4}$ We assume DUPV, UPV, wind, and hydropower plants have no variable cost.

For coal power plants not located at pithead locations or near coal mines, coal is generally transported by rail. In $2017,60 \%$ of coal consumed for electricity generation was transported through railways (Railway Board 2017). The cost of rail transport can result in large regional differences in the delivered cost of coal to thermal power plants. On average, rail transport accounts for over $85 \%$ of coal transportation costs (Kamboj and Tongia 2018). We account for these regional differences with a state-specific variable cost of generation for coal-fueled plants. This variable cost is based on an average pithead cost of 1.593 INR per kilowatt-hour (CEA 2019b) plus a transport charge. The transport charge captures the cost of delivered coal by rail and is calculated as the freight charge (INR/tonne) times the average fuel consumption for the coal fleet (tonne/MWh) (Kamboj and Tongia 2018). Figure 12 shows the regional differences in cost of delivered coal.

\footnotetext{
${ }^{4}$ We assume an exchange rate of 70.2 INR to 1 U.S. dollar.
} 


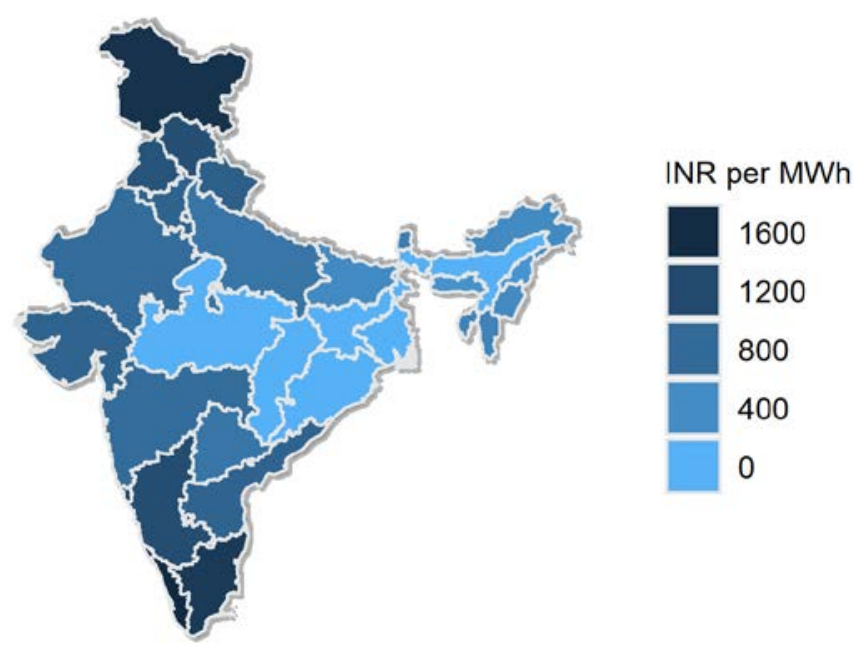

Figure 12. State-wise transport charge (INR/MWh) for coal delivered by rail

The transport charge is zero or very low in the Eastern Region, where most of India's coal mines are located. States in the north and south that are furthest from this region have the highest transport charges, which reflects the added distance the coal must travel by rail.

Plant heat rates are distinguished based on technology and include assumed efficiency improvements over time. Table 8 contains the average heat rate assumptions for all technologies.

Table 8. Technology Heat Rate Inputs

\begin{tabular}{lcl}
\hline Technology & $\begin{array}{c}2017 \text { Heat Rate } \\
\text { (GJ/MWh) }^{\mathbf{a}}\end{array}$ & Efficiency improvement \\
\hline CCGT gas & 7.3 & $0.20 \%$ annual improvement until 2030 \\
CCGT LNG & 7.3 & $0.20 \%$ annual improvement until 2030 \\
Cogeneration bagasse & 12.3 & None \\
Gas CT & 11.3 & $0.60 \%$ annual improvement until 2030 \\
Diesel & 11.5 & None \\
Subcritical coal & 11.1 & None \\
Subcritical lignite & 11.1 & None \\
Supercritical coal & 11.1 & $0.05 \%$ annual improvement until 2030 \\
\hline
\end{tabular}

a Value assumed for all plants commissioned in or before 2017

b Based on NREL 2018

Other operating parameters are expected to experience less variation between model regions and over time. Table 9 contains the input parameters assumed to remain constant for all BAs and model years. 
Table 9. Technology Operating Parameters Assumed Constant Across All Balancing Areas and Model Years

\begin{tabular}{lrcr}
\hline Technology & $\begin{array}{c}\text { Ramping Limits } \\
\text { (MW/min) }\end{array}$ & $\begin{array}{c}\text { Min. Loading } \\
\text { Fraction }\end{array}$ & $\begin{array}{c}\text { Planned/Unplanned } \\
\text { Outage (\%) }\end{array}$ \\
\hline CCGT gas & 3.4 & 0.50 & $2.4 / 8.5$ \\
CCGT LNG & 5.5 & 0.50 & $2.4 / 8.5$ \\
Cogeneration bagasse & 0.2 & 0.50 & $2.4 / 8.5$ \\
BESS & 15.3 & 0.00 & $0 / 0$ \\
Gas CT & 1.8 & 0.00 & $4.1 / 4.3$ \\
Diesel & 1.8 & 0.50 & $4.1 / 4.3$ \\
Hydro pondage & 10.5 & 0.00 & $0 / 0$ \\
Hydro pumped & 15.3 & 0.20 & $0 / 0$ \\
Hydro run of river & 5.4 & 0.00 & $0 / 0$ \\
Hydro storage & 8.2 & 0.00 & $0 / 0.7$ \\
Nuclear & 1.7 & 1.00 & $2.3 / 8.3$ \\
Subcritical coal & 3.8 & 0.55 & $5.1 / 10$ \\
Subcritical lignite & 1.5 & 0.55 & $5.1 / 10$ \\
Supercritical coal & 10.2 & 0.55 & $5.1 / 8$ \\
Solar PV & 0.0 & 0.00 & $0 / 0$ \\
WHR & 0.5 & 0.00 & $5 / 8.5$ \\
Wind & 0.0 & 0.00 & $0 / 0$ \\
\hline
\end{tabular}

In the Coal Flex scenario, the minimum loading for subcritical and supercritical coal plants is reduced to 0.4 to examine the impact of increased flexibility in India's coal fleet. 


\section{Text Box 2. Approximation of operational aspects of VRE Technologies}

As the penetration of VRE and storage technologies increases, more-detailed representation of system operations becomes increasingly important in planning. ReEDS addresses this through simulations of time-synchronous operations to estimate curtailment for each capacity expansion solution.

Curtailment is a reduction in generation from what a generator could otherwise produce given available resources. For VRE generators, curtailment can occur when there are high levels of inflexible "must-run" capacity committed or there is insufficient demand for the generation locally. Transmission congestion can also impact curtailment if network constraints prevent the export of excess power. The amount of curtailment may impact the economics of investment in VRE technologies.

The ReEDS curtailment module uses a statistical convolution approach to estimate the amount of VRE curtailment in each region and time-slice based on the expected value of (1) electricity demand, (2) minimum turn down of committed plants, (3) network flows, and (4) VRE generation. The output includes estimates of when and where curtailment is likely to occur for existing and candidate VRE technologies. Both (1) recommitting thermal capacity to change the minimum stable output level of the thermal fleet and (2) investing in energy storage and effectively increasing the available load could reduce curtailment levels. Therefore, the curtailment module also estimates the marginal impact of recommitting thermal capacity or adding new storage capacity on curtailment levels. This information is returned to the optimization problem to adjust the levels of VRE investments, storage investments, and dispatch decisions for the thermal fleet.

\section{Operating Constraints}

The operating constraints represent technical and resource-based limits on how technologies may be dispatched. These include (1) seasonal limits on hydropower generation, (2) limits on gas fuel supplies, (3) minimum loading for CCGT gas, and (4) seasonal minimum loading limits.

Seasonal rainfall patterns directly impact potential generation from hydropower plants throughout the year. We include seasonal capacity factors for each type of hydropower generator to account for variations in water available for hydropower generation. Using CEA's monthly generation data for more than 350 hydropower plants during 2015-2016 and 2016-2017 (CEA 2016a), we calculate average seasonal capacity factors for each plant in the report. We combine this with the power plant database from Palchak et al. (2017) and other publicly available sources to classify each plant as run-of-river, pondage, storage, or pumped, and we calculate the average capacity factor by plant type.

A shortcoming of this approach to estimating hydropower availability is that historical generation patterns are not based solely on water availability; hydropower generation may depend on other factors such as electricity demand and the availability of other generation resources. Improving the estimates for hydropower availability is an area for future work.

National fuel supply limits are imposed on gas technologies based on historical domestic and imported gas supplies. In the Base scenario, we assume no change in available gas supplies from 2017 (CEA 2019c). For the New Gas scenario, we assume new import terminals help ease supply restrictions over time. The maximum available gas supply is reached in 2024, after which the gas fuel limit remains constant through 2047 (Table 10). In both scenarios, gas fuel for new plants is assumed to come from imported LNG sources. 
Table 10. Fuel Supply Limits on Gas for the Base and New Gas Scenarios

Units are million metric standard cubic meter per day.

\begin{tabular}{lcc}
\hline Year & Base Scenario & New Gas Scenario \\
\hline $2017-2019$ & 20.0 & 20.0 \\
2020 & 20.0 & 71.6 \\
2021 & 20.0 & 89.0 \\
2022 & 20.0 & 105.9 \\
2023 & 20.0 & 123.5 \\
$2024-2047$ & 20.0 & 140.5 \\
\hline
\end{tabular}

Gas plant operations in India are limited by long-term fuel supply contracts. A gas supply contract typically takes the form of a "take-or-pay" agreement wherein daily gas delivery volumes are agreed on several months or years in advance of actual delivery. This type of fuel supply agreement prevents the gas fleet from adjusting unit commitment decisions based on daily, weekly, or seasonal variations in energy demand. To approximate the contractual limitations on the timing of gas fuel supply, the fleet of combined-cycle gas plants in each BA must generate in all times and seasons within a given year or not at all.

The constraint on timing of fuel supply is not imposed on open-cycle gas plants (CT gas). We assume CT gas plants can enter flexible fuel supply contracts that enable delivery of fuel when it is needed. We also assume necessary upgrades are made to the gas pipeline infrastructure, including compressor stations and pipeline network expansions, to enable flexible timing in the delivery of gas fuel for peaking plants. As with other technologies, the cost of new infrastructure investments to enable fuel delivery are assumed to be reflected in the plants' delivered fuel cost.

Finally, we impose minimum generation limits to restrict unrealistic plant cycling within each season. For any given season and BA, technologies that are dispatched must generate at or above their minimum loading level described in Table 9. This constraint prevents a situation where, for example, thermal capacity is dispatched during the morning peak, turned down to zero midday, and dispatched again to meet evening peak demand.

\subsubsection{Transmission}

ReEDS uses a reduced transmission network, capturing the aggregate carrying capacity of interstate lines between BAs based on Palchak et al. (2017), which represents a close approximation of existing capacity with reliability based flow limits. A transportation, or pipe flow model, approximates power flows between BAs. ${ }^{5}$ Figure 13 shows the available transfer capacities between BAs based on existing lines for 2017-2022.

\footnotetext{
${ }^{5}$ A transportation model ignores reactive power and Kirchhoff's current and voltage laws. We assume power flows from one region to the other without impacting the rest of the network.
} 


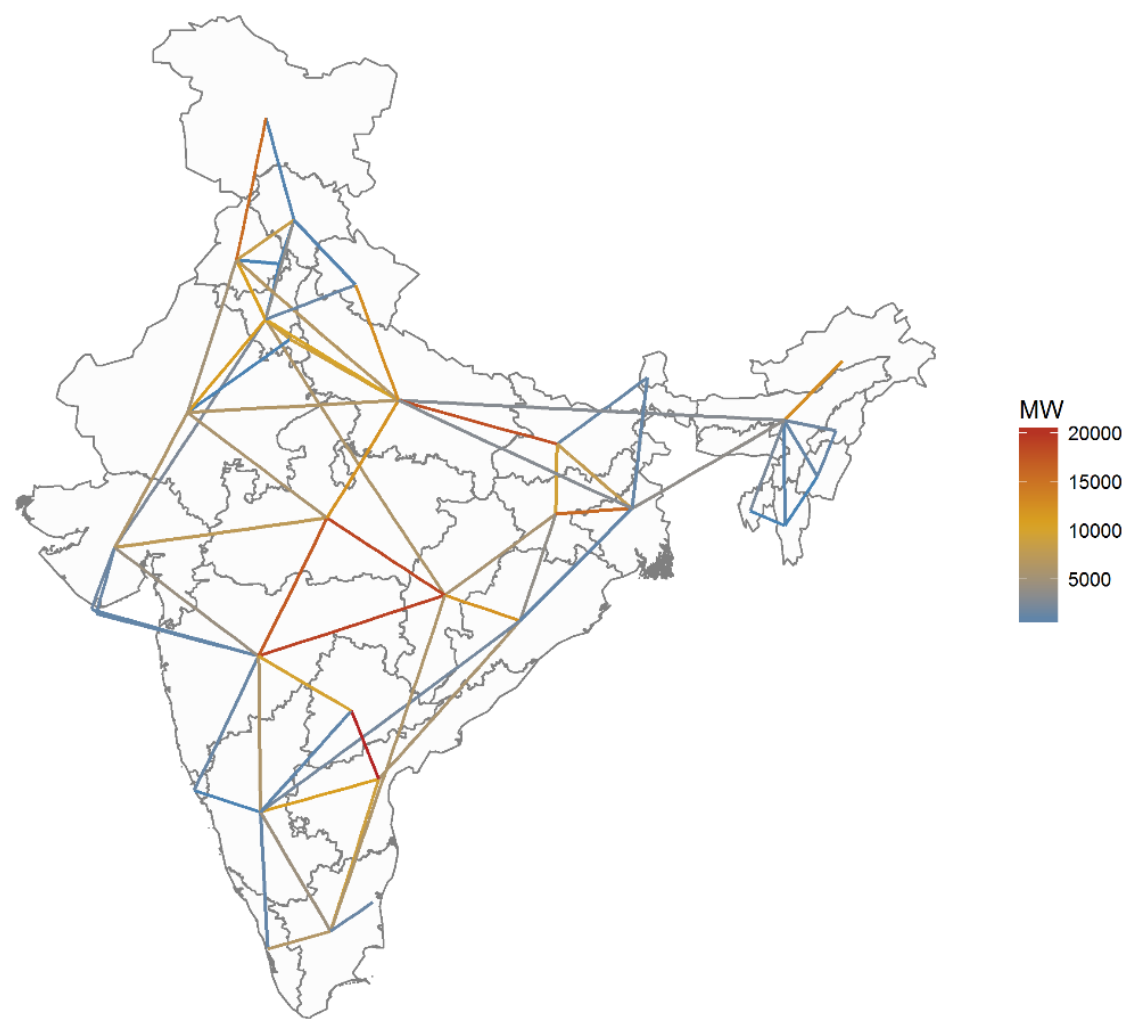

Figure 13. Transfer capacity available between BAs

\subsubsection{Transmission investments}

Transmission expansion in ReEDS is modeled as additional transfer capability (MW) between BAs built at a state-to-state-specific per unit cost (INR/MW-km). Using this approach, the total cost of adding transfer capacity between two BAs depends on the capacity being added and the distance between the BAs.

We estimate the capital cost for interstate lines based on the investment cost for the highest voltage line on each BA connection. In India, these voltages are $765 \mathrm{kV}, 400 \mathrm{kV}$, and $220 \mathrm{kV}$. Table 11 contains the capital cost assumptions for each voltage.

The final INR/MW-km values are obtained by dividing the per kilometer $(\mathrm{km})$ costs by the average carrying capacity of the interstate lines for that voltage in each BA. The distance between BAs is estimated using the population centers of each BA. The costs in Table 11 are national averages; each pair of BAs has its own transmission investment cost.

Table 11. Capital Costs for Select Transmission Voltages

\begin{tabular}{ccc}
\hline $\begin{array}{c}\text { Line Type } \\
\text { (kV) }\end{array}$ & $\begin{array}{c}\text { Capital Cost } \\
\text { (Lakh/km) }^{\mathbf{a}}\end{array}$ & $\begin{array}{c}\text { Average Transmission Cost } \\
\text { (INR/MW-km) }\end{array}$ \\
\hline 765 & 413 & 18,025 \\
400 & 124 & 21,915 \\
220 & 51 & 23,181 \\
\hline
\end{tabular}

a One Lakh denotes one hundred thousand rupees. 


\subsubsection{Substation Supply Curves}

The substation supply curves capture the cost of stepping up the voltage within a BA to reach the voltage of inter-BA transmission. The supply curves are an estimate of the costs of distributing power from large, high-voltage, inter-BA lines built by ReEDS to the existing intra-BA network. We assume new renewables can use existing infrastructure to step-up the voltage to the highvoltage buses to transmit their generation. If there are not enough buses to distribute/collect the power, the cost of purchasing new infrastructure is added to the total transmission cost.

The substation supply curves are based on the cost of transformers (INR/MW) at different voltage levels and an estimate of how much line capacity (MW) can be tied into a specific bus. The final supply curve consists of a carrying capacity (MW) and marginal cost (INR/MW) for each voltage class by BA. The carrying capacity is calculated as the number of substations in each BA at a specified voltage times the carrying capacity for that voltage. The marginal cost to distribute power in each BA is equal to the cost to step up the voltage from each voltage class to the inter-BA transmission voltage. The transmission supply curves inform decisions about necessary network investments and siting decisions for new generation; they do not replace the need for detailed transmission planning supported by power flow analysis.

\subsubsection{Reliability}

Based on current national regulations, we include two types of reliability constraints: planning reserves and operating reserves. A planning reserve margin of $15 \%$ of peak demand is enforced every year (CEA 2019c). ${ }^{6}$ The amount of installed capacity considered "firm," or available to contribute to the planning reserve margin requirement, depends on the technology type.

Conventional generation technologies receive full capacity credit toward meeting the planning reserve margin with no seasonal variation. The firm capacity for dispatchable hydropower plants (i.e., hydro pondage and storage plants) is based on the installed capacity times the average seasonal capacity factor for that technology. For VRE and storage technologies, firm capacity is estimated based on hourly simulations of generation and demand to determine each technology's contribution to reduce the coincident peak net load in each region and season.

The operating reserve requirement is equal to $5 \%$ of national demand in each time-slice. The contribution of different technologies to the operating reserve requirement is limited by the ramping capability for that technology. The assumptions for operating reserve costs and technology-specific contributions are based on Cohen et al. (2019).

\footnotetext{
${ }^{6}$ The planning reserve margin is taken as an exogenously assigned requirement. Assessing the appropriate level of reserve requirements is an area for future work and outside the scope of this study.
} 
Table 12. Input Assumptions for Operating Reserve Costs and Capabilities

\begin{tabular}{lcc}
\hline Technology & $\begin{array}{l}\text { Cost of Operating Reserve } \\
\text { Provision (INR/MW) }\end{array}$ & $\begin{array}{l}\text { Contribution of Capacity to Operating } \\
\text { Reserve Requirement (\%) }\end{array}$ \\
\hline CCGT gas & 421 & 30 \\
CCGT LNG & 421 & 30 \\
Gas CT & 281 & 30 \\
Diesel & 281 & 20 \\
Hydro pumped & 140 & 100 \\
Hydro storage & 140 & 100 \\
Subcritical coal & 702 & 10 \\
Subcritical lignite & 702 & 10 \\
Supercritical coal & 1,053 & 10 \\
\hline
\end{tabular}

\subsection{Data Limitations and Areas for Model Improvement}

Substantial effort, including multiple meetings with CEA representatives to review the model inputs and assumptions, was made to collect detailed data on the important characteristics of India's existing and planned power system. However, some assumptions are needed wherever data are incomplete or unavailable. While many of these assumptions are unlikely to significantly impact the model results and findings, confidence in the results can be improved through a more accurate representation of certain inputs. Improvements that can be incorporated in future studies include:

- Improved data accuracy and fidelity for generator costs and capabilities, including:

- Additional years of generation data for hydropower plants

- India-specific capital costs for all candidate generation technologies

- Operating reserve capabilities based on assessment of Indian generators

- Geographic location and historical generation data for existing wind and solar plants

- Fuel availability for specific gas-fired plants and locations

- Cost and resource data for candidate offshore wind sites

- Improved data on transmission network costs and capabilities, including:

- Geospatial map of bulk transmission network

- Capital cost data for transmission lines and substations at select voltage levels. 


\section{Results}

This section presents the results of ReEDS India modeling to examines the development of the India power system to 2047 under a Base scenario (Section 3.1) and multiple alternative scenarios (Section 3.2) that explore uncertainty in future component costs, fuel availability, and technology performance.

\subsection{Base Scenario}

Anticipated changes in electricity demand and component costs can drive a significant shift in the electricity supply of India's power system and how the system will be operated. The Base scenario reflects a future in which technology cost trajectories follow current trends and demand grows according to CEA projections. This scenario provides insight into what might be a plausible future for India's electric power system given very little change in policy or technology development; the scenario also helps provide a business-as-usual case to measure how sensitive the future is to changes in costs, fuel availability, or other system parameters.

\subsubsection{Installed Capacity}

In the Base scenario, the total installed capacity over the planning period increases from $299 \mathrm{GW}$ in 2017 to $1,718 \mathrm{GW}$ in 2047 . Figure 14 shows the evolution of the country's installed capacity over the modeling period. Capacity additions and retirements are fixed based on current plans through 2022. After that, the model optimizes the capacity mix in each year to achieve a leastcost system.

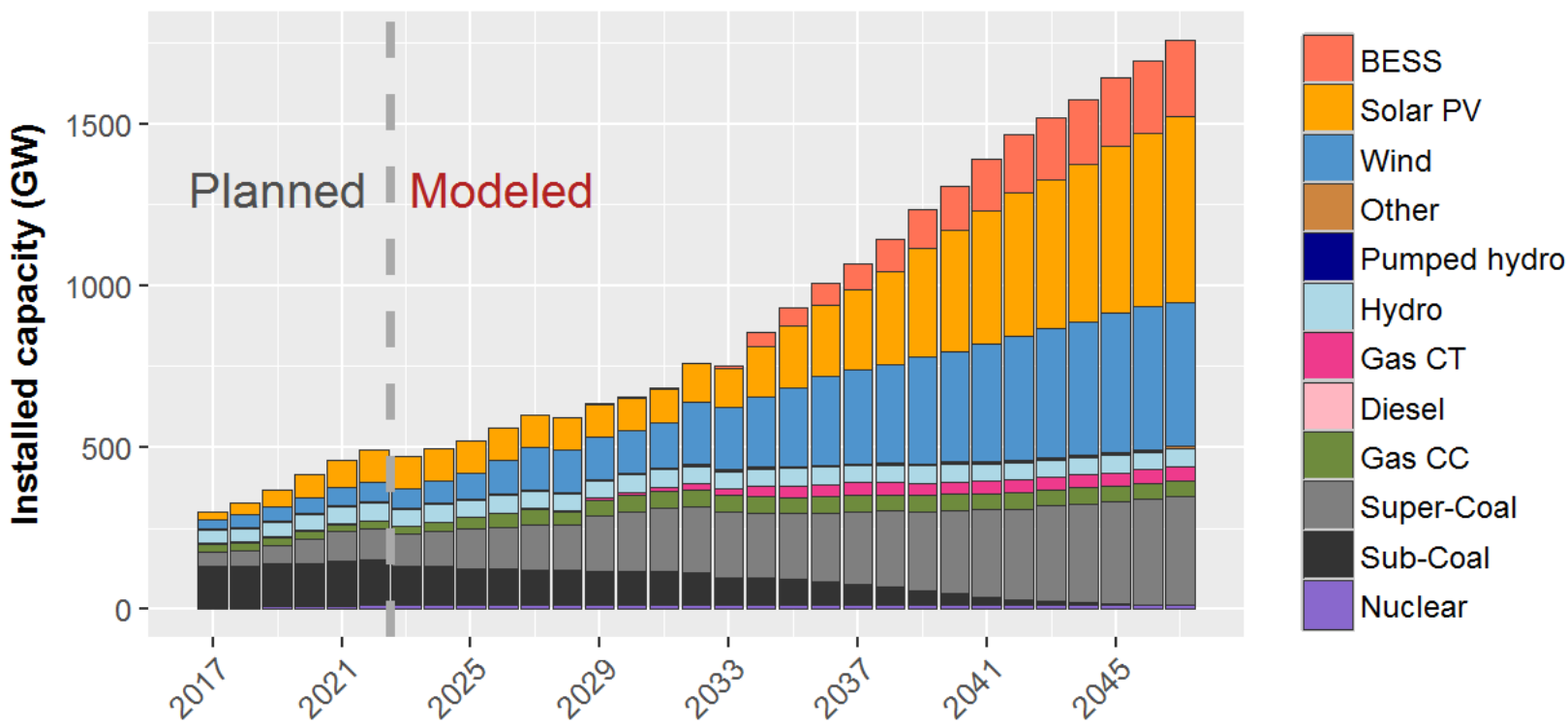

Figure 14. Total installed capacity, 2017-2047 in the Base scenario 
Based on guidance from CEA, all subcritical coal and diesel plants are retired by 2047. Most new investments are from supercritical coal, wind, solar PV and BESS technologies. Figure 15 summarizes the net annual investments by technology, differentiating prescribed and economic investments. Prescribed investments, outlined in red, are capacity additions already underway or planned that are exogenously assigned. Economic investments, outlined in black, are investment decisions based on least-cost criteria.

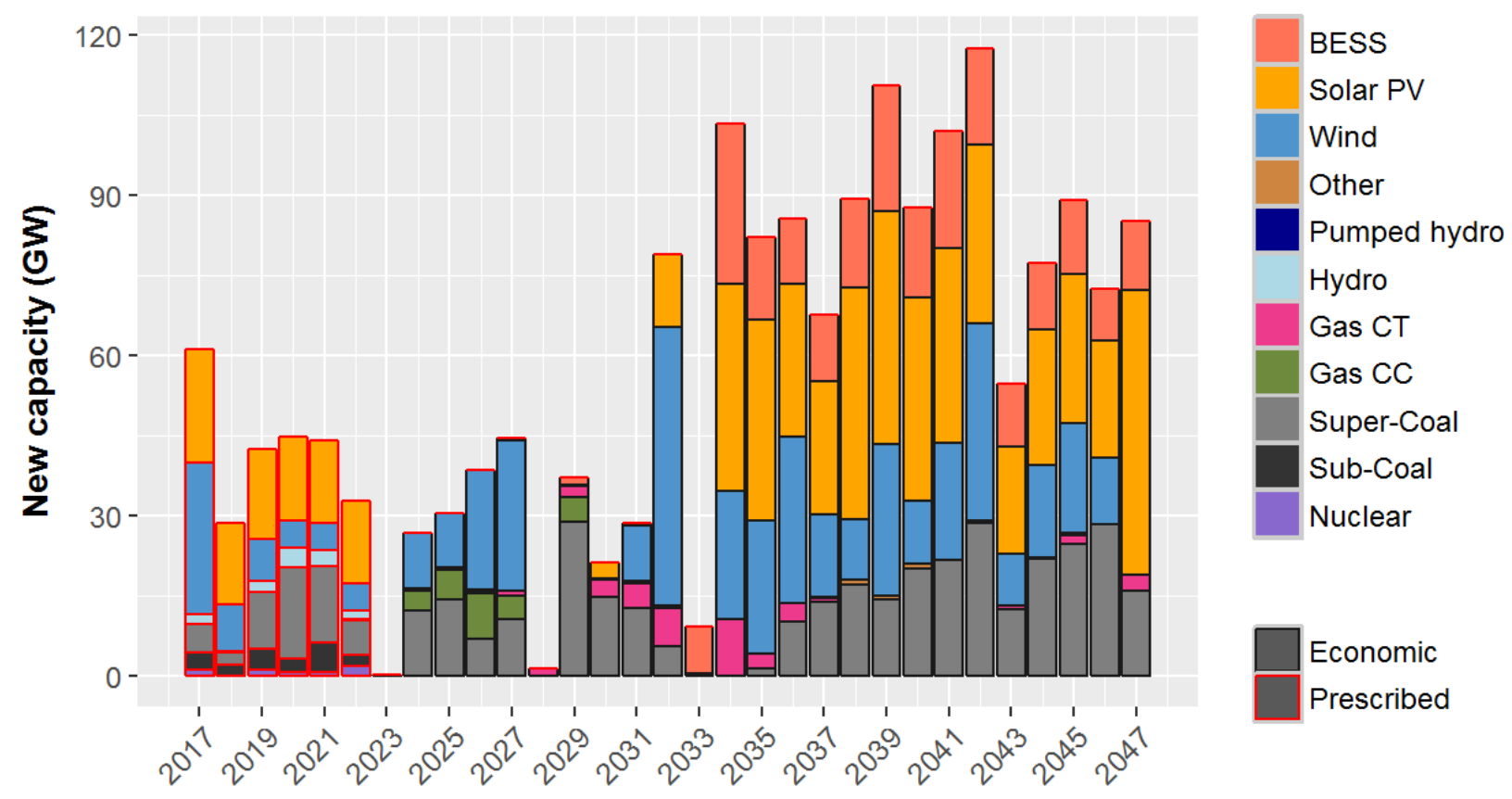

Figure 15. Annual capacity additions, Base scenario

In the initial years, prescribed additions for projects already underway and required RE additions to meet India's 175-GW RE target account for all the capacity additions. After 2022, there are no prescribed additions and all investments reflect economic, least-cost capacity additions. Initially, between 2022 and 2029, gas CC technologies are added to provide firm capacity to meet the planning reserve margin. Gas technologies are good candidates for providing firm capacity because they are less expensive to build than other conventional technologies. Beginning in 2029, gas CT capacity is added to provide peaking capacity as well as contribute to the planning reserve margin. Gas CT plants have more generation dispatch flexibility and are better suited than gas $\mathrm{CC}$ plants to operate as peaking plants with very low utilization. Investments in wind, solar PV, and BESS account for most capacity additions after 2034; the fraction of installed capacity from solar and wind increases from 17\% in 2017 to 58\% in 2047. Supercritical coal and BESS also play a larger role in the future capacity mix, accounting for $19 \%$ and $13 \%$ of installed capacity in 2047 respectively. Table 13 illustrates how the installed capacity changes over time. 
Table 13. Evolution of Installed Capacity by Technology, Base Scenario

\begin{tabular}{|l|r|r|r|r|r|r|}
\hline \multirow{2}{*}{ Technology } & \multicolumn{2}{|c|}{$\mathbf{2 0 1 7}$} & \multicolumn{2}{c|}{$\mathbf{2 0 3 0}$} & \multicolumn{2}{c|}{$\mathbf{2 0 4 7}$} \\
\cline { 2 - 7 } & $\mathbf{G W}$ & $\mathbf{\%}$ of total & $\mathbf{G W}$ & \% of total & $\mathbf{G W}$ & \% of total \\
\hline BESS & - & - & 2 & $\sim 0$ & 237 & 13 \\
\hline Solar PV & 21 & 7 & 103 & 16 & 575 & 33 \\
\hline Wind & 29 & 10 & 131 & 20 & 445 & 25 \\
\hline Other & 1 & $\sim 0$ & 1 & $\sim 0$ & 5 & $\sim 0$ \\
\hline Pumped hydro & 3 & 1 & 3 & $\sim 0$ & 3 & $\sim 0$ \\
\hline Hydro & 43 & 14 & 54 & 8 & 54 & 3 \\
\hline Gas CT & $<1$ & $\sim 0$ & 9 & 1 & 5 & 2.5 \\
\hline Diesel & 1 & $\sim 0$ & - & - & - & - \\
\hline Gas CC & 24 & 8 & 51 & 8 & 49 & 3 \\
\hline Super-Coal & 46 & 15 & 184 & 28 & 336 & 19 \\
\hline Sub-Coal & 125 & 42 & 106 & 16 & - & 0 \\
\hline Nuclear & 7 & 2 & 11 & 2 & 11 & 1 \\
\hline Total & 299 & & 656 & & 1,718 & \\
\hline
\end{tabular}

Significant investments in BESS begin after 2030 in the Base scenario as a results of falling capital costs and increasing deployment of wind and solar resources, which are complemented by BESS's ability to shift energy from high-RE periods to high-load periods. BESS also contributes to the planning reserve margin. Figure 16 shows the mix of installed capacity that contributes to the planning reserve margin. By 2030, wind contributes $32 \mathrm{GW}$ to the planning reserve margin requirement in April-June. In 2047, solar, wind, and BESS together account for 39\% of the firm capacity requirements in October-November and $47 \%$ in December-January.

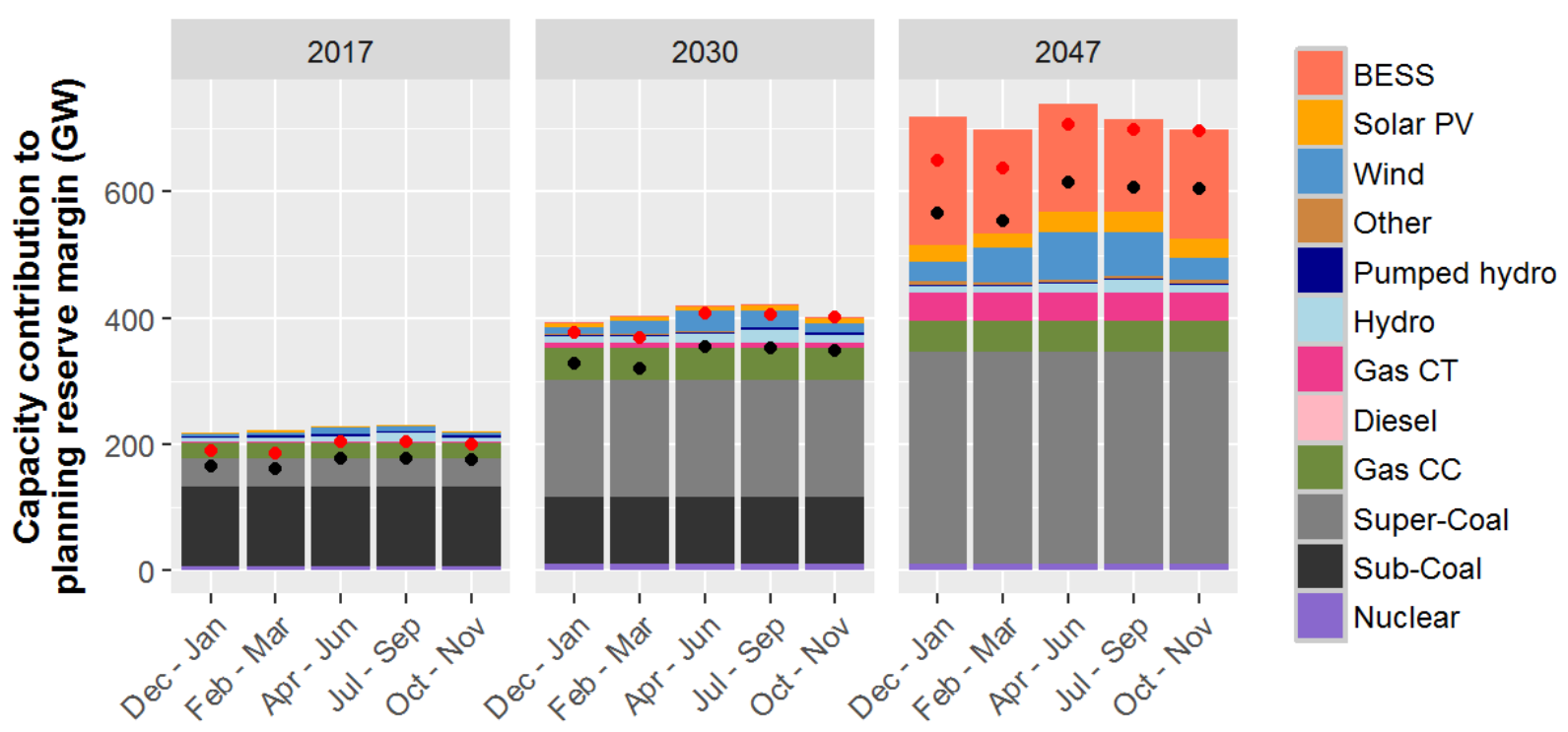

Figure 16. Change in capacity that is used to meet the planning reserve margin, Base scenario

Black dots indicates peak national demand, and red dots indicate the planning reserve margin requirement. 
It is notable in Figure 16 that, in a future system with high penetrations of RE, capacity additions are driven by the coincidence of demand and RE generation rather than peak demand alone. By 2047, the system has surplus capacity during the peak demand months of July-September because high wind speeds mean more wind generation is available to meet peak demand in these months. New capacity is needed to meet peak demand during the moderate demand months of October and November, when wind generation is lower.

In addition to changes at the national level, the future capacity mix may shift at the regional level. Figure 17 shows the change in installed capacity for each of India's five operating regions.

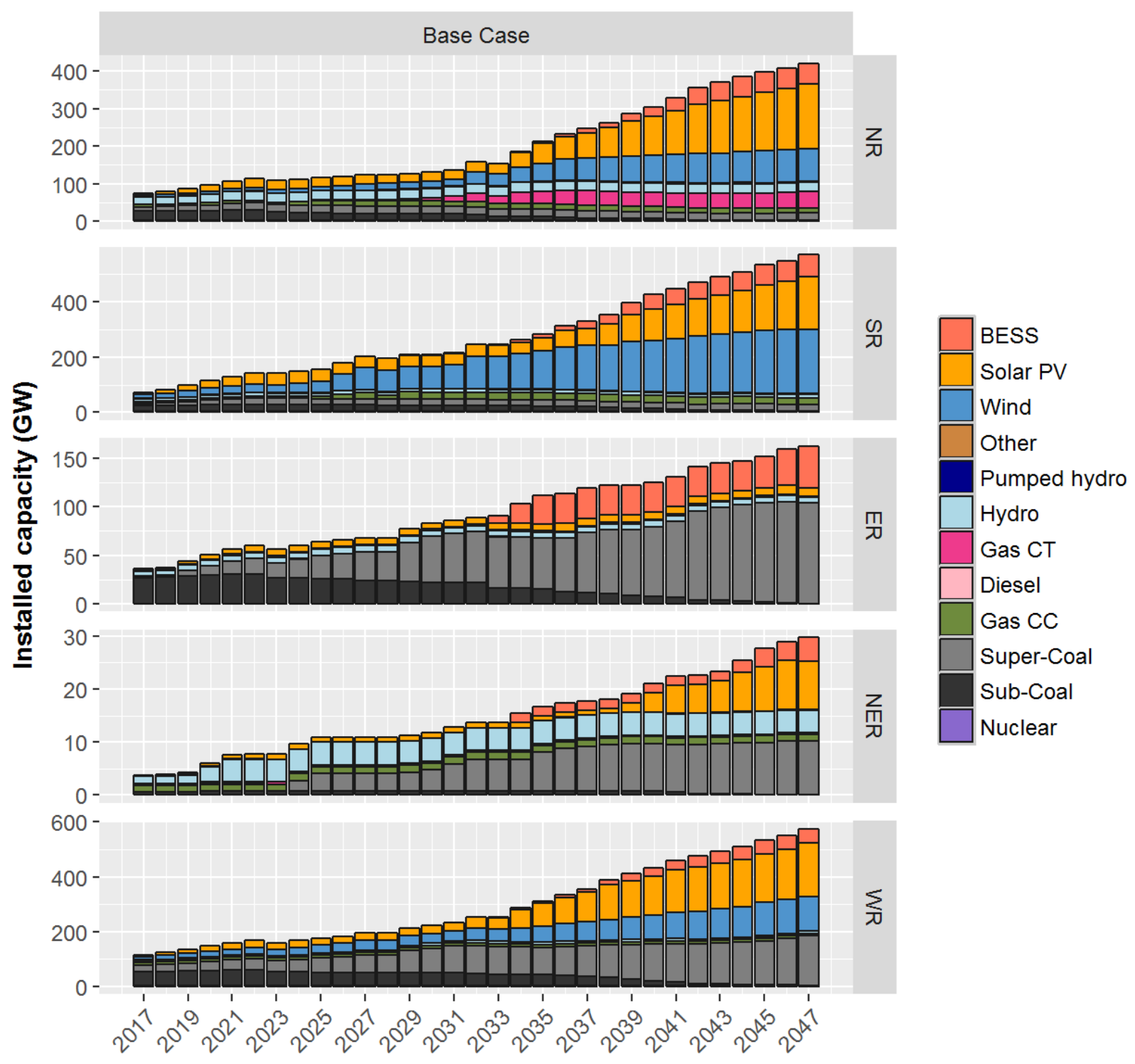

Figure 17. Change in installed capacity by region, Base scenario

Y-axis scales differ between plots. 
All regions see major changes in their capacity mix with increasing reliance on solar PV, wind, BESS. The largest wind, solar, and BESS additions take place in the Northern, Southern, and Western Regions. Coal remains dominant in the Eastern Region because its coal fuel prices are lower than the rest of the country. In the Northeastern Region, increasing demand is met with supercritical coal and solar PV paired with BESS. Gas CT capacity is concentrated in the Northern Region to provide a peaking resource. Gas CC capacity contributes to the planning reserve margin in Uttar Pradesh and high RE states in the Western and Southern Regions. Figure 18 shows the installed capacity of gas and coal capacities in 2047 by state.

a

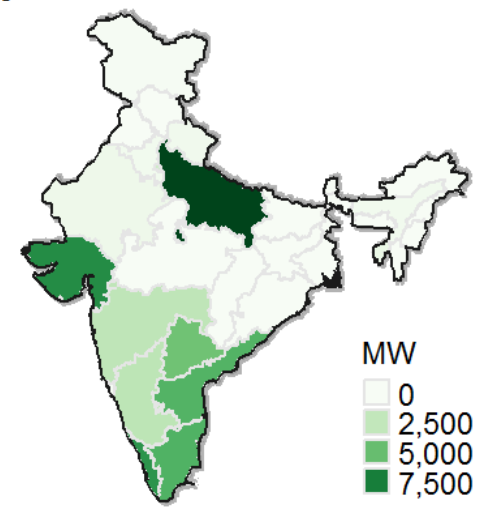

b

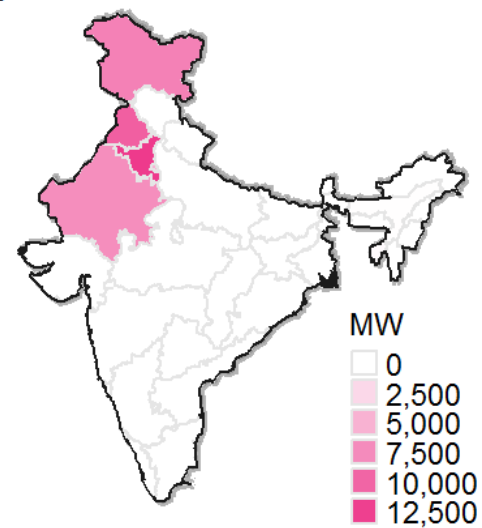

C

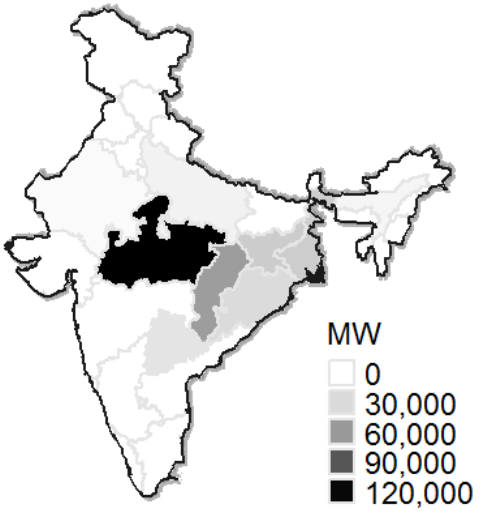

Figure 18. Location of (a) Gas CC, (b) Gas CT, and (c) Supercritical-coal in 2047, Base scenario

By 2047, more than 1,000 GW of wind and solar PV are deployed in the Base scenario. This capacity is concentrated in areas with the best resource and lowest grid connection cost (Figure 19). Most of the wind capacity is concentrated in six states in the Southern and Western Regions: Gujarat, Rajasthan, Jammu and Kashmir, and Karnataka together host 59\% of all UPV capacity, and the remaining $41 \%$ is dispersed over 27 other states. Investments in DUPV capacity are driven by national rooftop solar targets.

a

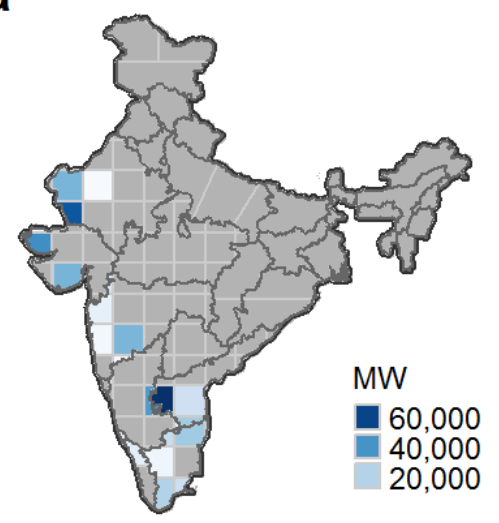

b

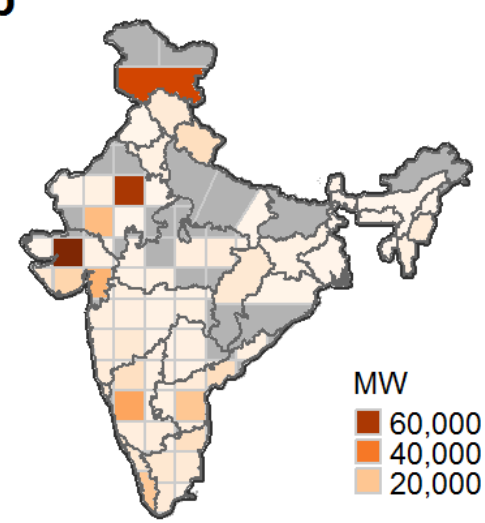

C

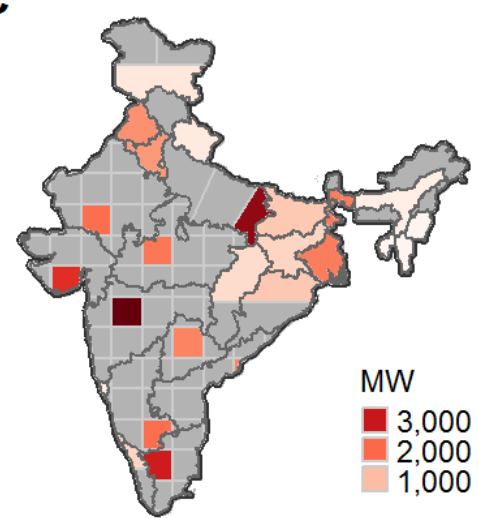

Figure 19. Location of (a) Wind, (b) UPV, and (c) DUPV capacity in 2047, Base scenario 


\subsubsection{System Operations}

Supercritical coal, wind, and solar PV play an increasing role in meeting electricity demand in the Base scenario. Figure 20 shows the evolution of the generation mix over the planning period.

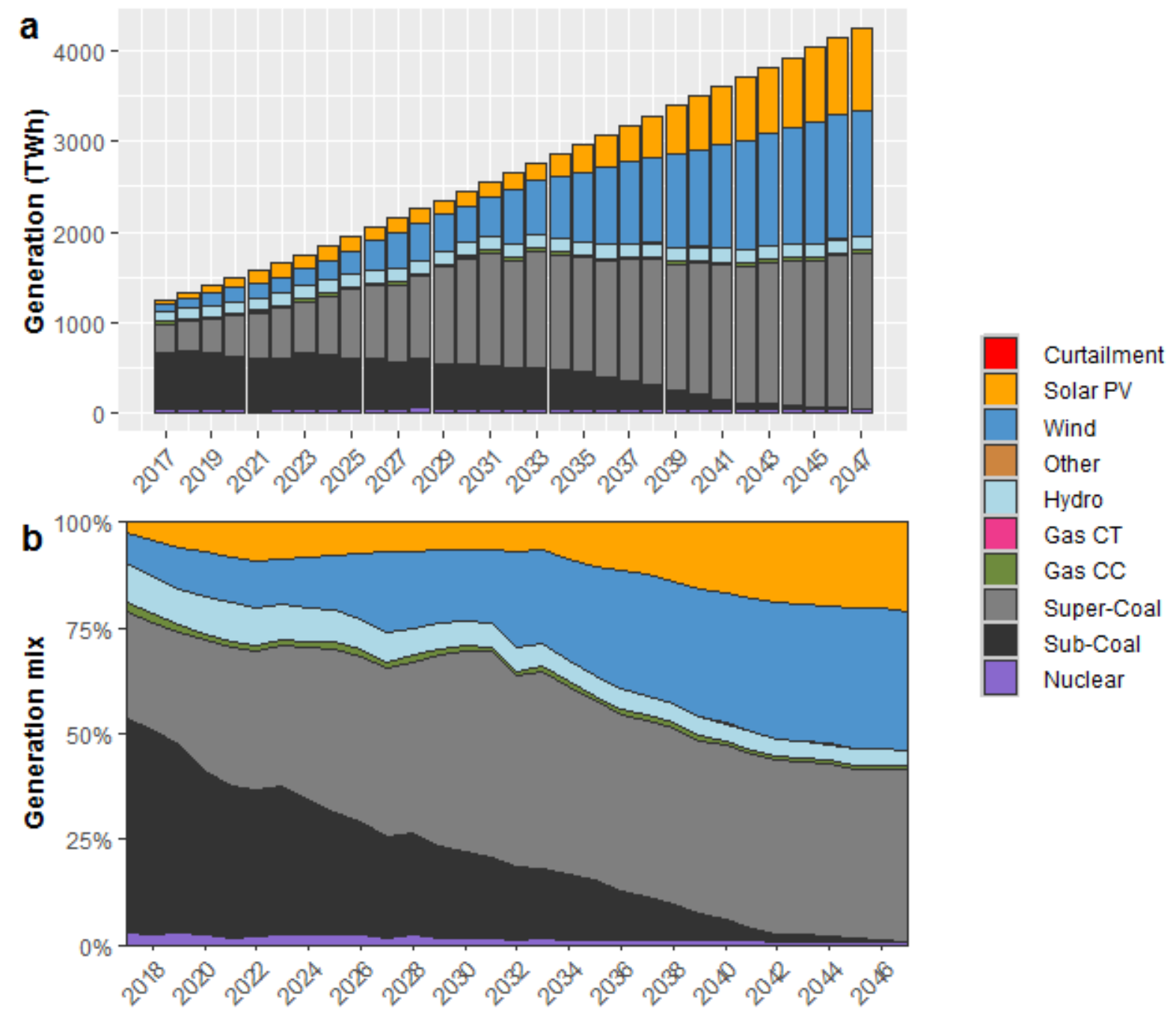

Figure 20. Absolute (a) and relative (b) annual generation mix for 2017-2047, Base scenario

In response to national efforts to shift from subcritical to supercritical coal technologies, generation from supercritical coal increases from $26 \%$ in 2017 to $41 \%$ in 2047 . The energy contribution of VRE technologies increases from 10\% in 2017 to $54 \%$ in 2047. In some years, a small amount of VRE energy $(<1 \%)$ cannot be absorbed by the system and is curtailed. Table 14 illustrates how the generation mix changes over time. 
Table 14. Evolution of Generation Mix (Percentage of Total) by Technology, Base Scenario

\begin{tabular}{lrrr}
\hline Technology & $\mathbf{2 0 1 7}$ & $\mathbf{2 0 3 0}$ & $\mathbf{2 0 4 7}$ \\
\hline Solar PV & 3 & 7 & 21 \\
Wind & 7 & 17 & 33 \\
Other & $\sim 0$ & $\sim 0$ & $\sim 0$ \\
Pumped hydro & $\sim 0$ & $\sim 0$ & $\sim 0$ \\
Hydro & 9 & 6 & 3 \\
Gas CT & $\sim 0$ & $\sim 0$ & $\sim 0$ \\
Diesel & $\sim 0$ & $\sim 0$ & $\sim 0$ \\
Gas CC & 2 & 1 & 1 \\
Super-Coal & 26 & 48 & 41 \\
Sub-Coal & 51 & 20 & 0 \\
Nuclear & 3 & 2 & 1 \\
\hline
\end{tabular}

Comparing Table 13 and Table 14, we see that gas $\mathrm{CT}$ and gas $\mathrm{CC}$ technologies contribute around $6 \%$ of installed capacity but only $1 \%$ of annual generation in 2047 . These technologies have high operating costs and are only dispatched during a few high-demand periods or when other technologies are unavailable. Figure 21 (next page) shows the evolution of technologies dispatched and net demand in each time-slice between the 2022 and 2047 model years.

For each representative hour, the black dot indicates the total electricity demand (GW) and the bar chart shows the mix of generation sources dispatched to meet demand during that period. The pink dot shows net demand (demand less dispatched wind and solar PV), which is the required contribution of dispatchable technologies and energy storage.

By 2047, BESS plays a key role in maximizing the use of excess solar PV generation by storing energy during the day (i.e., the bars in Figure 21 are higher than the black dots) and discharging during peak demand or evening periods when solar generation is unavailable. When net demand is close to zero or below zero, BESS also plays a key role in shifting excess energy from thermal plants that are constrained by the minimum generation level. The system also experiences seasonal changes in the mix of resources used to meet demand. Wind generation is highest in April-September, displacing output from supercritical coal. During the low-wind season in October-November, total generation from wind falls $77 \%$ compared to August-September, requiring increased output from supercritical coal, nuclear, and gas $\mathrm{CC}$ technologies to meet demand. 


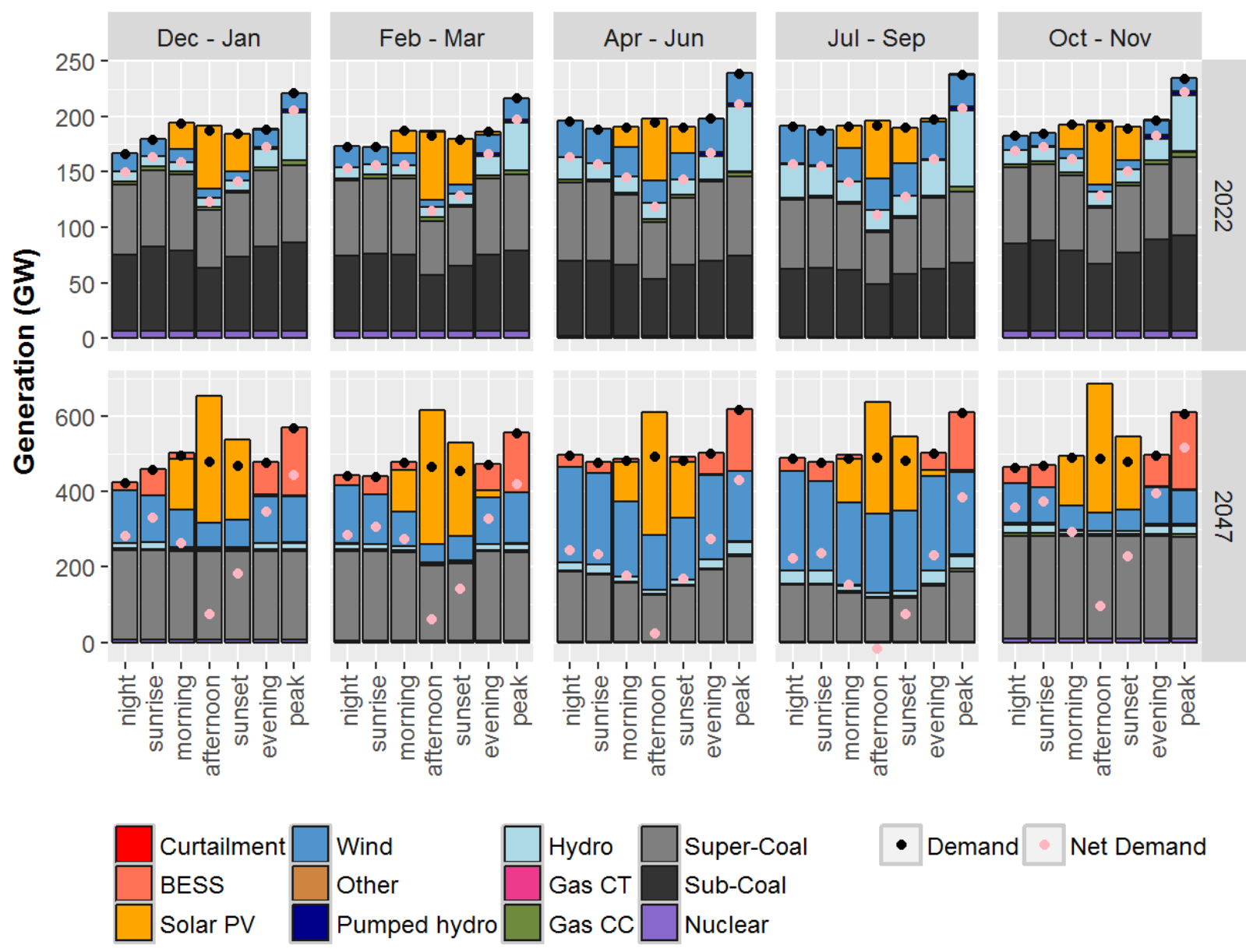

Figure 21. Time-slice generation for the 2022 and 2047 model years in the Base scenario

$\mathrm{Y}$-axis scales differ between plots. 


\subsubsection{Transmission Investments and Interstate Trade}

Investments in interstate transmission enable high-RE states to evacuate excess energy around the country. Figure 22 maps (a) investments in new transmission and (b) maximum interstate power flows for 2047.

a

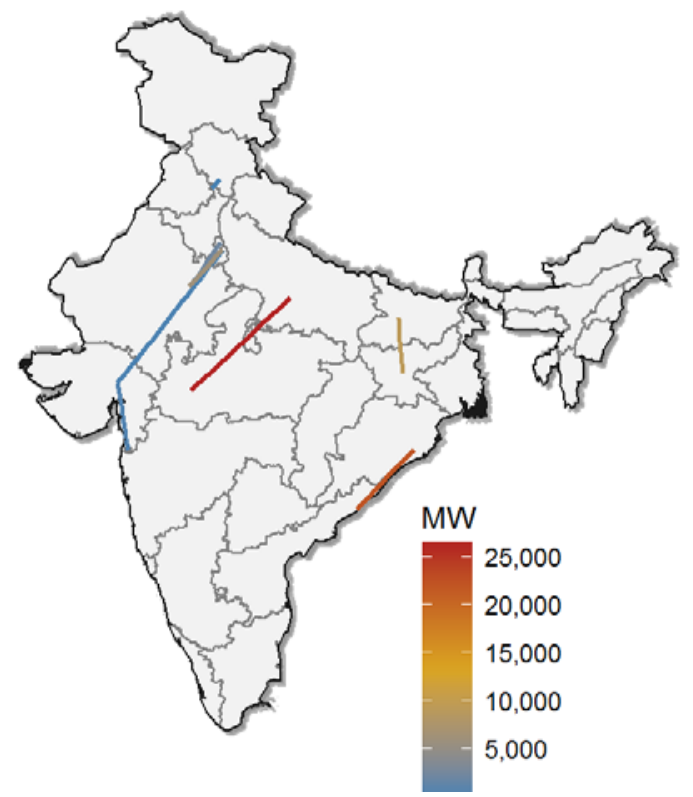

b

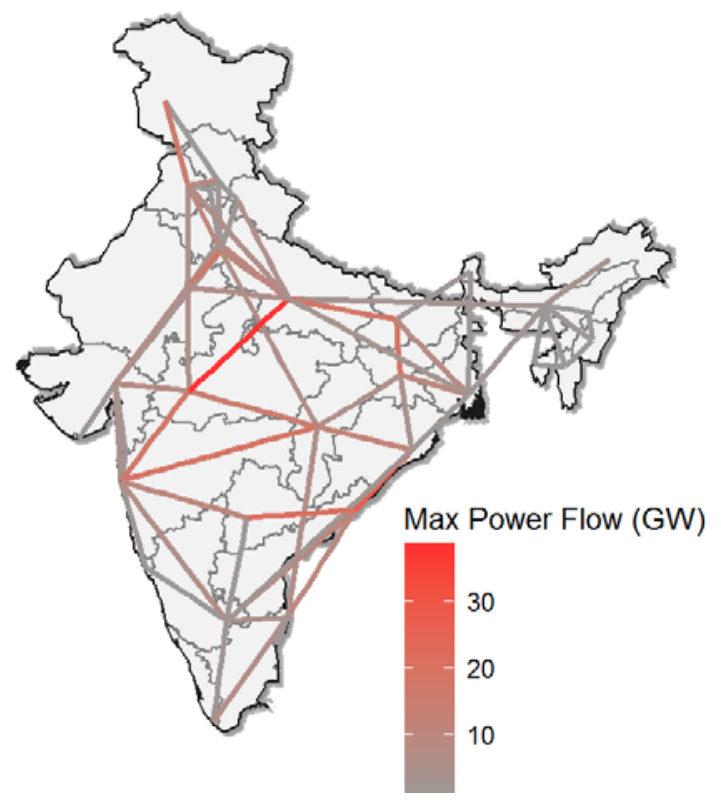

Figure 22. Total interstate (a) transmission capacity investments and (b) power flow in 2047, Base scenario

The largest increases in transmission capacity are between Madhya Pradesh and Uttar Pradesh and between Odisha and Andhra Pradesh. While Madhya Pradesh in the center of the country has limited RE capacity — coal accounts for $85 \%$ of the state's installed capacity in 2047 - it serves as a central corridor through which excess RE generation is transmitted from the Western Region to the Northern and Eastern Regions. In both the highest wind and highest solar generation periods, the largest power flows are from Madhya Pradesh to Uttar Pradesh in the north. The increase in transfer capacity between Odisha and Andhra Pradesh allows excess wind generation in the Southern Region to be exported to the Eastern Region.

These results provide insight as to how power flows across the country may change in response to changes in the generation mix and the resulting need for network reinforcements. Moredetailed power flow studies would be required to inform investment decisions.

\subsubsection{Carbon Emissions}

India has pledged a $33 \%-35 \%$ reduction in the emissions intensity of its economy from 2005 to 2030 (UNFCCC 2015). Reducing emissions from the electric power sector is a critical element of this goal. In the Base scenario, total emissions increase over the planning period as the amount of total electricity generated increases significantly. However, the emissions intensity decreases 47\%, from 0.76 metric tonnes of carbon dioxide per megawatt-hour in 2017 to 0.40 in 2047 . Carbon emissions from the production of electricity also become more concentrated in a few states (Figure 23). 

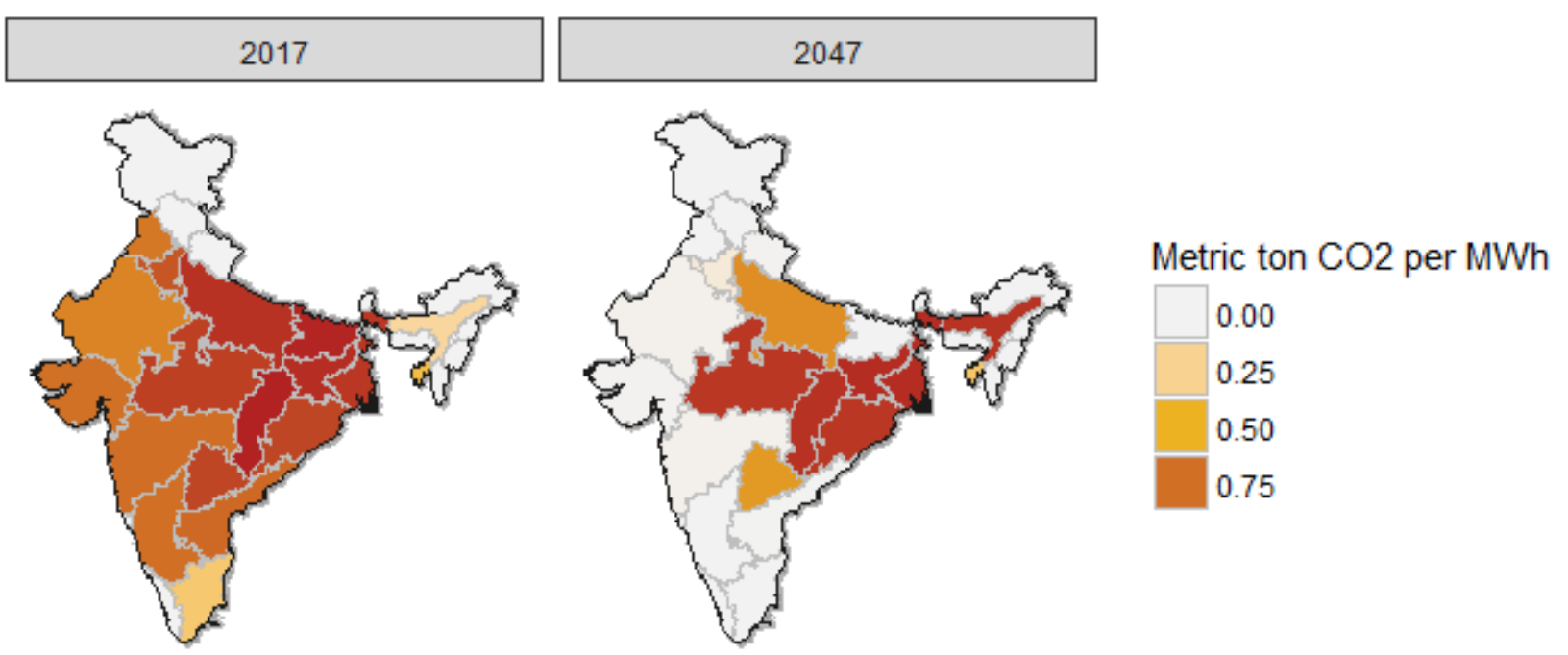

Figure 23. Carbon emissions intensity from electricity production by state, 2017 and 2047

Though electricity production is concentrated within these states, power is being sent around the country. Emissions from electricity production are typically attributed to offtakers.

In 2017, coal generation in almost all states contributes to the production of carbon dioxide emissions across the country. By $2047,99 \%$ of carbon emissions are concentrated in eight states, primarily in the Eastern Region, where coal remains cost-competitive with other technologies. While the emissions from electricity production are typically attributed to the offtakers, which could be anywhere in the country, the redistribution and concentration of coal-fired generation may help alleviate air quality problems in Uttar Pradesh and Bihar but may lead to even greater air quality concerns in neighboring states, particularly Madhya Pradesh, Jharkhand, Odisha, West Bengal and Chhattisgarh.

\subsection{Alternative Scenario Results}

For the Indian power system, there is uncertainty about how technology costs, fuel availability, technology capabilities, and demand may evolve over time. To understand how these uncertainties may impact system needs and help inform investment decisions that are robust against a variety of uncertainties, we tested the alternative scenarios described in Table 1.

\subsubsection{Technology Cost}

The alternative cost trajectories include a range of lower capital costs for solar PV, battery storage and wind technologies. The capital cost in the low-cost solar PV scenarios range from $10 \%$ to $50 \%$ lower by 2047 than in the Base Case, including cost declines for both utility-scale solar power plants and distributed solar PV. Cost scenarios for BESS technologies range from $10 \%$ to $50 \%$ lower capital cost by 2047 lower than the Base Case, and wind cost scenarios range from $10 \%$ to $40 \%$ lower capital cost by 2047 . Figure 24 shows how the penetration of VRE in India's generation mix changes with different capital cost projections for BESS, solar PV, and wind technologies. 


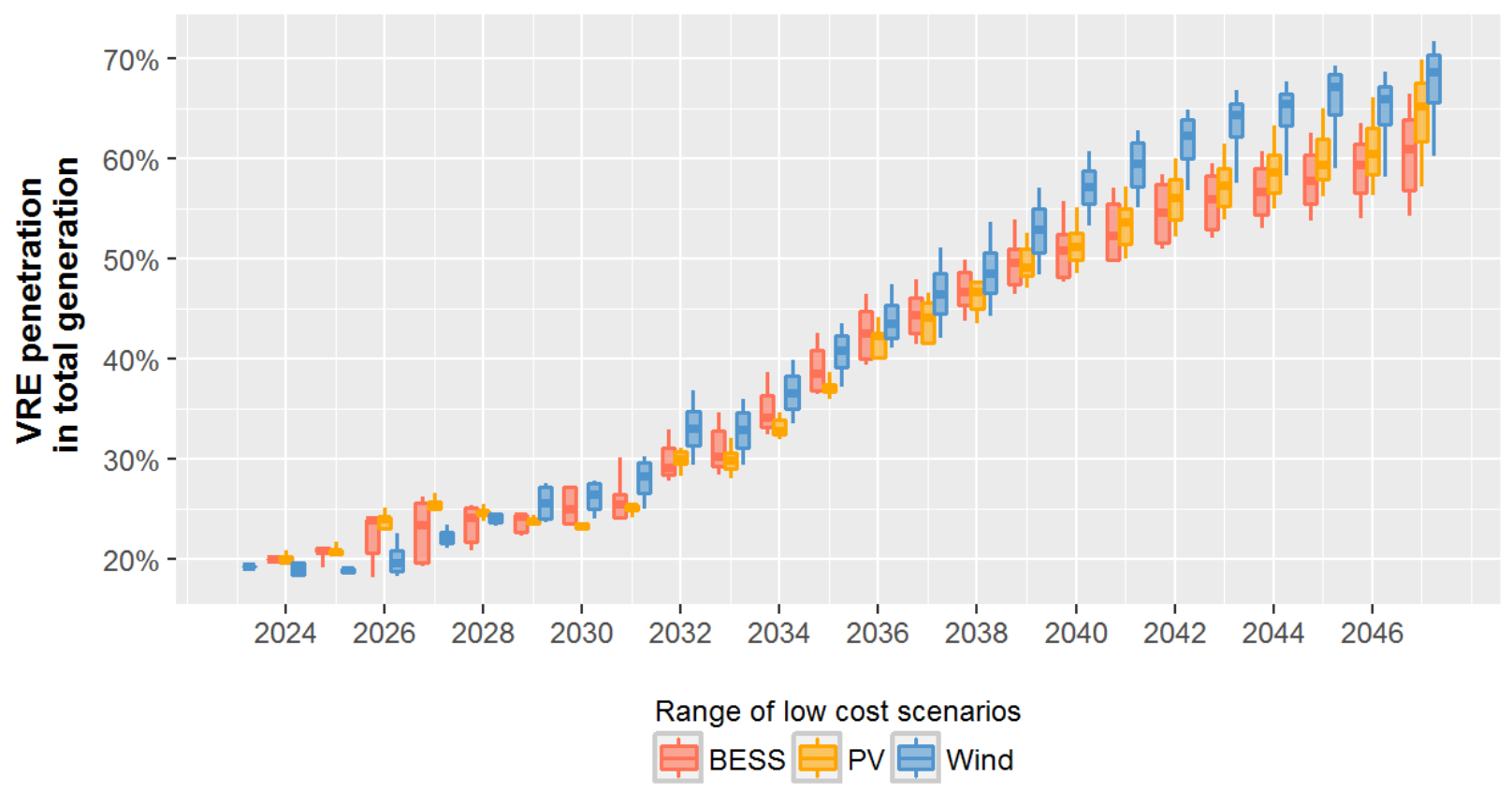

Figure 24. Range of VRE penetration in total generation in each model year in the BESS, solar PV, and wind technology cost scenarios

Boxes represent divisions into 25 th percent quartiles. The middle line is the median.

Reducing the capital cost of wind has a larger impact on VRE penetration than reducing the costs of BESS or solar PV. The lowest wind cost scenario (40\% capital cost decline by 2047 relative to the Base scenario) results in the highest annual penetration of VRE in the final generation mix. Table 15 compares the annual penetration of VRE by 2047 in the Base scenario and three lowest technology cost scenarios. Table 15 also compares the average fleet load factors for thermal technologies, which is a measure of the annual fleet-wide utilization of installed capacity. Compared to the Base scenario, the lowest wind cost scenario (Wind-40) has the largest impact on thermal fleet utilization.

Table 15. VRE Penetration in Annual Generation and Average Fleet Load Factors for Thermal Technologies by 2047

\begin{tabular}{|l|c|c|c|c|}
\hline \multirow{2}{*}{ Scenario } & \multirow{2}{*}{$\begin{array}{c}\text { VRE Penetration } \\
\text { in Annual } \\
\text { Generation, 2047 }\end{array}$} & \multicolumn{3}{|c|}{$\begin{array}{c}\text { Average Fleet Load Factors for } \\
\text { Thermal Technologies }\end{array}$} \\
\cline { 3 - 5 } & $54 \%$ & Coal & Gas & Nuclear \\
\hline Base & $66 \%$ & $59 \%$ & $5 \%$ & $37 \%$ \\
\hline BESS-50 & $70 \%$ & $57 \%$ & $6 \%$ & $37 \%$ \\
\hline PV-50 & $72 \%$ & $41 \%$ & $6 \%$ & $36 \%$ \\
\hline Wind-40 & & & $2 \%$ & $26 \%$ \\
\hline
\end{tabular}


Figure 25 presents the results of total capacity installed in each year through 2047 between the Base Case and the lowest-cost scenario for each technology: 50\% lower solar PV cost, 50\% lower BESS cost, and 40\% lower wind cost. Annual investments in new capacity from 2017 to 2030 are lower than in later years (Figure 15). As a result, the largest impact of the technology cost scenarios begins after 2030, when lower costs for select technologies impacts a greater number of investment decisions.

After 2030, wind, solar, and BESS dominate new capacity investments across all technology cost scenarios. Notably, in both the Lower Solar Costs and Lower Battery Costs scenarios, the installed capacity of BESS exceeds that of supercritical coal by 2040.
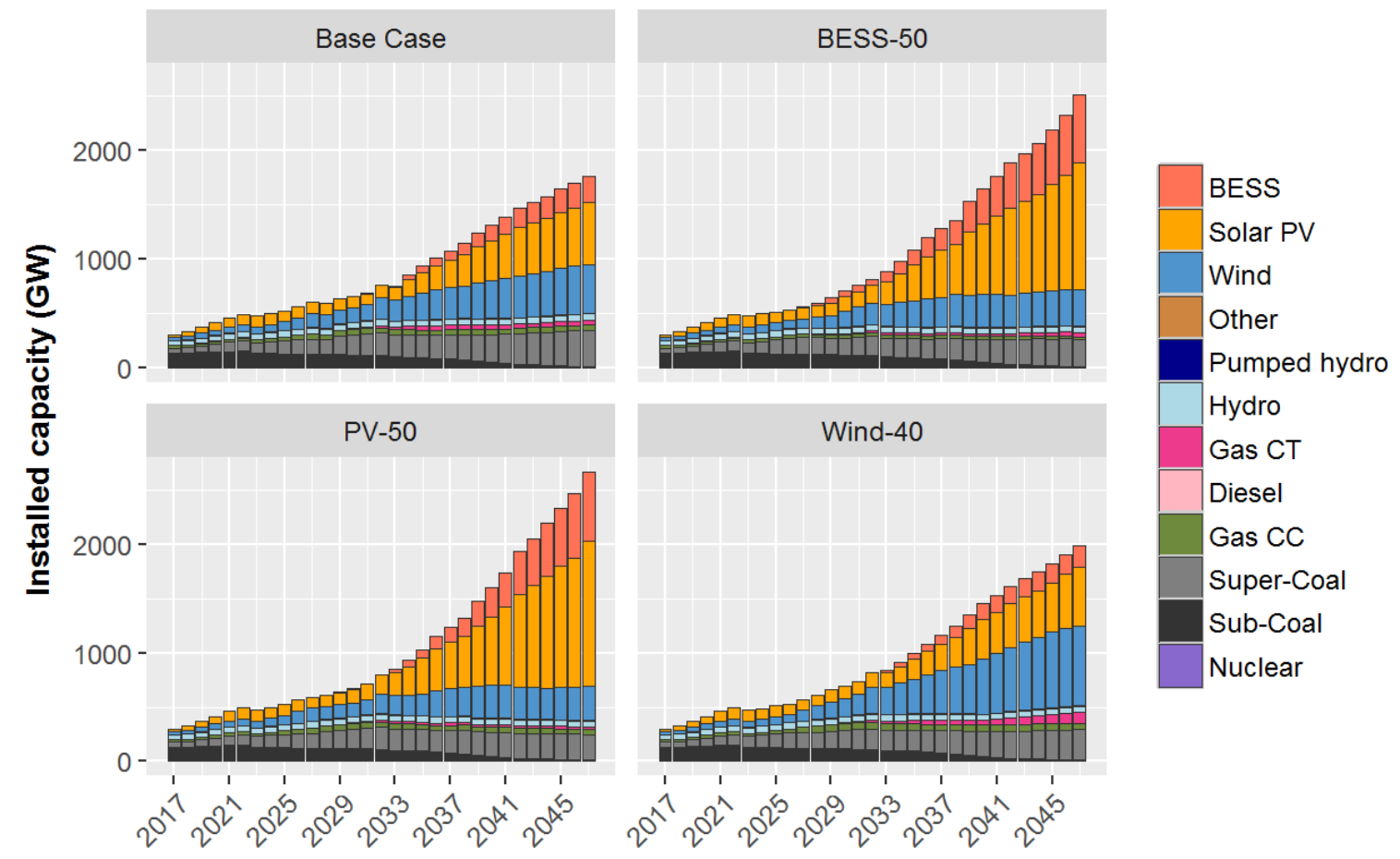

Figure 25. Total capacity installed through 2047 in the Base, Lowest Solar Cost, Lowest Battery Cost, and Lowest Wind Cost scenarios

The technology cost scenarios show that changes in capital costs can lead to very different investment pathways. Solar PV and BESS are complementary technologies; decreasing the cost of one tends to increase investments in both. By contrast, solar PV and wind are competing technologies; lowering the cost for one tends to reduce investments in the other. In all scenarios, lower capital costs for BESS, solar PV, and wind primarily displace supercritical coal capacity in favor of VRE. The low solar cost (PV-50) scenario has the largest impact, displacing $100 \mathrm{GW}$ $(30 \%)$ of supercritical coal and $20 \mathrm{GW}$ of gas CT with solar PV and BESS. Unlike the other technology cost scenarios, reducing wind costs (Wind-40 scenario) actually increases investments in gas CT to provide energy in October-November, when wind output is low. 
A key driver of the different investment pathways is the correlation between solar and wind generation and electricity demand. Figure 26 compares the generation by time-slice in the Base, low battery cost (BESS-50), low solar cost (PV-50), and low wind cost (Wind 40) scenarios.

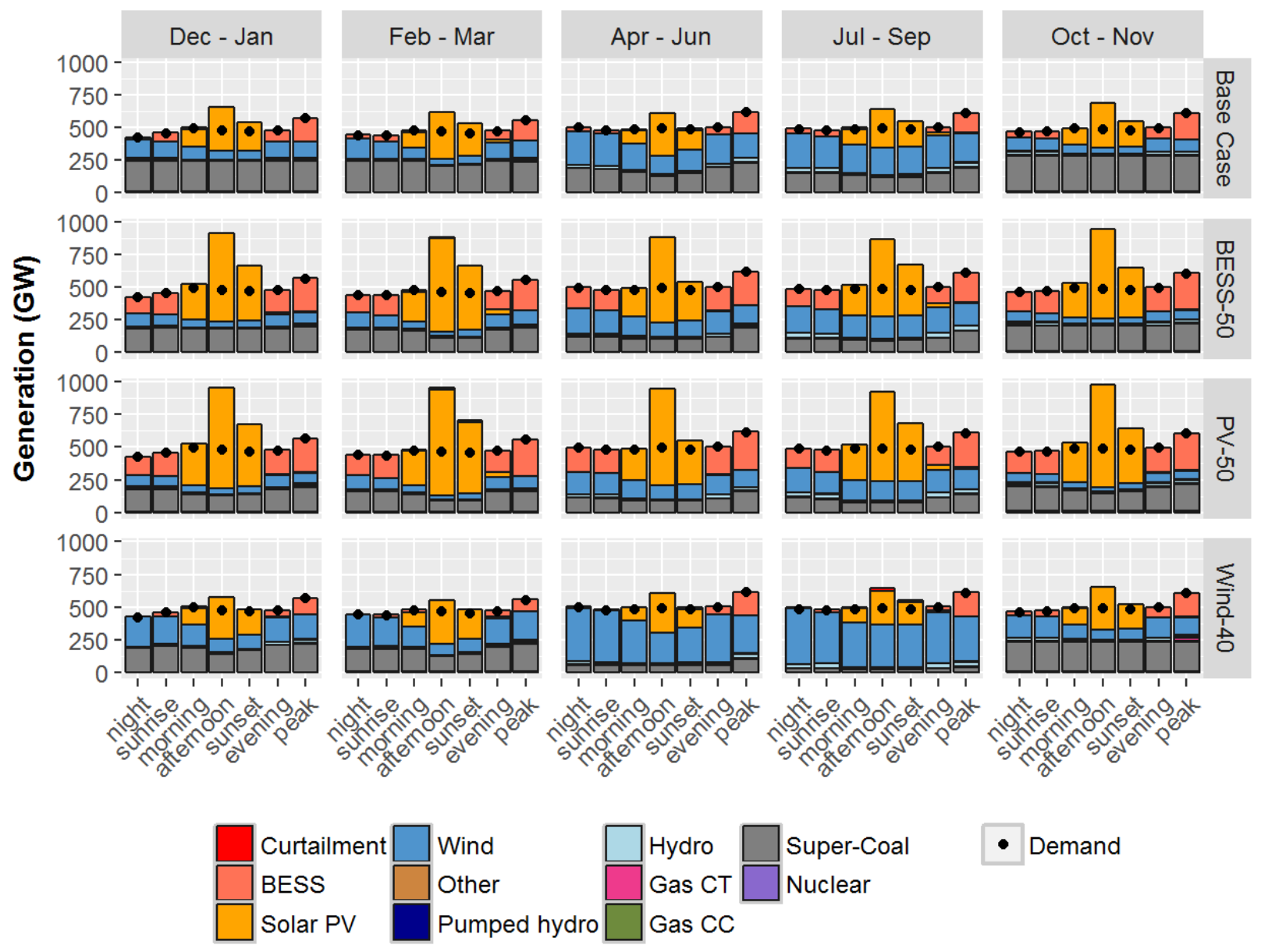

Figure 26. Comparison of 2047 time-slice generation for the Base, Low Battery Cost (BESS-50), Low Solar Cost (PV-50) and Low Wind Cost (Wind-40) scenarios

As previously mentioned, peak demand is forecast to occur in the evenings, when solar PV is unavailable. With BESS, excess solar generated during daytime hours can be stored and dispatched during evening peak hours. This has two implications for capacity investments. First, there is less need for investments in gas CT to meet demand during peak hours. Second, building more solar PV is economic because output from the plants can be shifted to times of day when it is most needed. Wind generation, by contrast, is available throughout the day but the level of output varies seasonally requiring some capacity to be available for a small number of months in the year.

The Low Wind Cost scenario has the largest impact on transmission investments. By 2047, more than $100 \mathrm{GW}$ of interstate transfer capacity is added in the Low Wind Cost scenario, compared with $68 \mathrm{GW}$ in the Base scenario. Figure 27 shows the total transmission investments by 2047 in the Base and Low Wind Cost scenarios. 


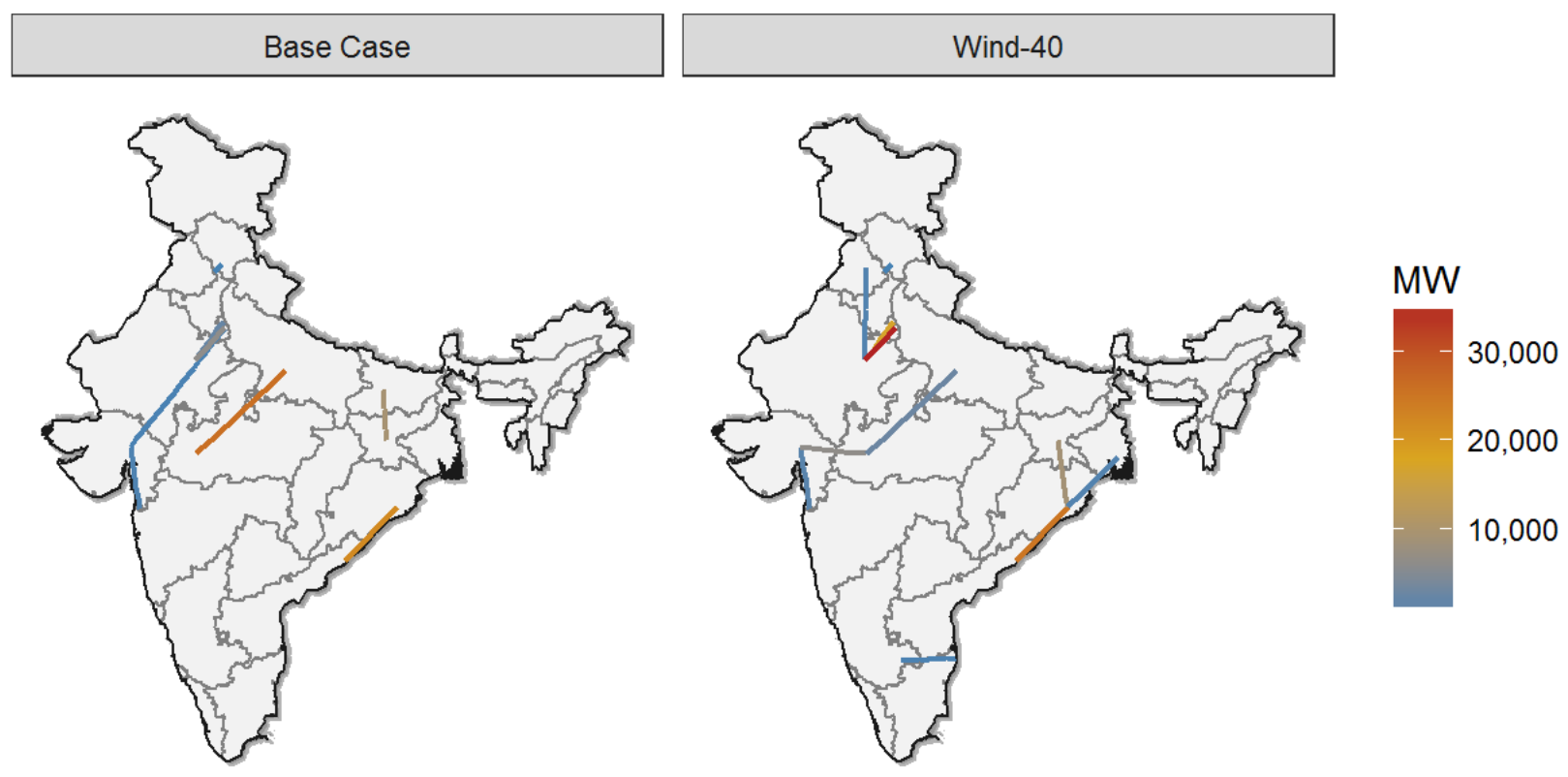

Figure 27. Transmission capacity investments by 2047 in the Base and Low Wind Cost scenarios

The Low Wind Cost scenario results in significantly more transmission capacity between Rajasthan, a high-wind state, and load centers in Delhi and Haryana. New transmission investments between Rajasthan and Delhi reach more than 17,000 MW by 2047, compared with 2,300 MW in the Base scenario. Transmission investments between Rajasthan and Haryana total nearly 35,700 MW of new capacity, compared with 6,300 MW in the Base scenario. There is also $900 \mathrm{MW}$ of added transmission capacity between Rajasthan and Punjab, which helps further increase the export of wind power to northern states while enabling Rajasthan to import electricity during low-wind periods. Another difference with the Base scenario is the transmission investment between Gujarat and Madhya Pradesh, which enables Gujarat, another high-wind state, to export excess wind generation to other states in the Western Region. During low-wind periods, Gujarat imports electricity from Madhya Pradesh, which remains a coaldominant state in the Low Wind Cost scenario. Additional transmission investments are also added within the Eastern Region between Odisha and West Bengal (900 MW), and between Odisha and Jharkhand (8,900 MW), enabling the Southern Region to wheel more excess wind to the Eastern Region through Odisha. A small transmission investment of $500 \mathrm{MW}$ is also added between Tamil Nadu and Karnataka to enable export of excess wind power from Tamil Nadu.

\subsubsection{New Gas Fuel Availability Scenario}

In the New Gas scenario, we assume increased import terminals result in more gas being available for electricity production in future years. We assume gas prices will remain constant compared to the Base scenario, as the cost of new infrastructure to enable fuel delivery are assumed to be reflected in plants' delivered fuel costs. Despite increased gas supply, we do not see significant changes in the capacity or generation mix by 2047. The high cost of gas plant operation results in $82 \%-89 \%$ of new gas fuel available for the power sector remaining unused in the New Gas scenario. This suggests the future of gas for electricity production in India is less constrained by fuel availability than by cost competitiveness with other technologies. 


\subsubsection{Improved Coal Flexibility Scenario}

In the Coal Flex scenario, we investigate the impact of improvements in the technical capabilities of India's coal fleet to achieve a minimum generation level of $40 \%$ from its current level of 55\%. The results show the flexibility of India's coal fleet has a marginal impact on how the system will evolve over our extended planning horizon. Coal fleet flexibility results in a slight increase $(6 \mathrm{GW})$ in investments in solar PV, which represents a $1 \%$ increase over the Base scenario. More significantly, the deployment of BESS is delayed: large-scale investments (more than $1 \mathrm{GW}$ nationally) in BESS begin in 2033, four years later than in the Base scenario. Increasing flexibility from the coal fleet provides sufficient operational flexibility to delay BESS investments until later years, when the installed costs of BESS declines and solar PV penetration increases. Another impact of increased coal flexibility is a 5.6-GW decrease in gas CT investments and 5.2-GW increase in gas CC investments. Fewer gas CT investments are needed because the coal fleet combined with new investments in gas $\mathrm{CC}$ provides a lower-cost source of flexibility and sufficient firm capacity than the Base scenario. Investments in other technologies, transmission investments, and system operations remain largely unchanged. 


\section{Conclusions}

The supply of electricity in India is poised to undergo significant changes over the coming decades. A system previously dominated by subcritical coal plants could rely increasingly on supercritical coal, wind, and solar technologies. In this analysis, we find $95 \%$ of electricity demand could be met by these three technologies by 2047.

As electricity supplies become more concentrated in areas with strong variable renewable energy (VRE) resources, new interstate transmission capacity is needed to evacuate excess power to neighboring states. This concentration also has implications for carbon emissions, which become increasingly concentrated in a few Eastern Region states where coal remains cost-competitive with other technologies.

Lower capital costs for wind have a larger impact on VRE penetration than reducing the costs of BESS or solar PV. This is because wind resources are better correlated than solar resources with the seasons and times of day when demand is highest. However, wind resources experience very high seasonal variability. Increasing wind capacity (Wind-40 scenario) actually increases investments in gas CT to provide energy in October-November, when wind output is low. Future work will explore the interactions of technology cost trends in more detail.

In the near term, there is still an opportunity for gas technologies, particularly during peak demand hours or seasons with low wind speeds. However, battery storage plants are anticipated to outcompete gas plants as a peaking resource by 2047. Increasing the availability of gas for electricity generation does not significantly impact the capacity or generation mix by 2047 . In fact, over $80 \%$ of the new gas fuel available for the power sector is unused in the New Gas scenario, which suggests the future of gas for electricity production in India will be driven by cost competitiveness rather than fuel availability. Similarly, increasing the flexibility of India's coal fleet has a marginal impact on how the system will evolve over an extended planning horizon.

The results from this long-term assessment are pertinent for a variety of decision makers. For example, policymakers must establish the policy and regulatory frameworks needed to enable cost-effective investments and system operations. And the results can allow utilities, project developers, and financing institutions to anticipate system changes and mobilize necessary expertise and funding to realize their long-term vision. Finally, the evolution of the power system is of interest to the broader public who will be impacted by issues related to land use, electricity prices, quality of supply, emissions, and domestic jobs in the energy sector. 


\section{References}

BNEF (Bloomberg New Energy Finance). 2017. Accelerating India's Clean Energy Transition: The Future of Rooftop PV and Other Distributed Energy Markets in India. BNEF. November 2017. https://data.bloomberglp.com/professional/sites/10/BNEF Accelerating-Indias-CleanEnergy-Transition_Nov-2017.pdf.

\section{- 2019. Battery Storage in India: Entering the Decade of Growth. BNEF. August 2019.}

CEA (Central Electricity Authority of India). 2016a. Hydro Generation Performance Data 201617. Delhi: CEA. September 2016.

http://www.cea.nic.in/reports/others/hydro/hpi/hydro performance_data.pdf.

- 2016b. Draft National Electricity Plan: Volume I: Generation. Delhi: CEA.

December 2016. http://www.cea.nic.in/reports/committee/nep/nep dec.pdf.

- 2018a. Load Generation Balance Report 2018-19. Delhi: CEA. July 2018.

http://www.cea.nic.in/reports/annual/lgbr/lgbr-2018.pdf.

- 2018b. $19^{\text {th }}$ Electric Power Survey. Delhi: CEA.

—. 2018c. National Electricity Plan: Volume I: Generation. Delhi: CEA. January 2018. http://www.cea.nic.in/reports/committee/nep/nep_jan_2018.pdf.

—. 2018d. Status of Hydroelectric Potential Development. Delhi: CEA. March 2018.

- 2019a. All India Installed Capacity (in MW) of Power Stations (As on 31.05.2019). Delhi: CEA. http://www.cea.nic.in/reports/monthly/installedcapacity/2019/installed capacity$\underline{\text { 05.pdf }}$

- 2019b. February 2019. Draft Report on Optional Generation Capacity Mix for 2029-30. Delhi: CEA. http://cea.nic.in/reports/others/planning/irp/Optimal_generation_mix_report.pdf

- 2019c. In person meeting at CEA headquarters. Central Electricity Authority, Sewa Bhawan, R. K. Puram, Sector-1, New Delhi. July 2019.

Cohen, Stuart, Jon Becker, Dave Bielen, Maxwell Brown, Wesley Cole, Kelly Eurek, Will Frazier, et al. 2019. Regional Energy Deployment System (ReEDS) Model Documentation: Version 2018. Golden, CO: National Renewable Energy Laboratory. NREL/TP-6A20-72023. https://www.nrel.gov/docs/fy19osti/72023.pdf.

Kamboj, Puneet, and Rahul Tongia. Indian Railways and Coal: An Unsustainable Interdependency. Brookings India. July 2018. https://www.brookings.edu/wpcontent/uploads/2018/07/Railways-and-coal.pdf. 
Maclaurin, Galen, Nick Grue, Anthony Lopez, and Donna Heimiller. 2019. The Renewable Energy Potential (reV) Model: A Geospatial Platform for Technical Potential and Supply Curve Modeling. Golden, CO: National Renewable Energy Laboratory. NREL/TP-6A20-73067. https://www.nrel.gov/docs/fy19osti/73067.pdf.

MNRE (Ministry of New and Renewable Energy). 2018. "Year End Review 2018: MNRE." Delhi: Press Information Bureau, Government of India. December 10, 2018. http://pib.nic.in/newsite/PrintRelease.aspx?relid=186228

NREL (National Renewable Energy Laboratory). 2018. "2018 Annual Technology Baseline." Golden, CO: National Renewable Energy Laboratory. https://atb.nrel.gov/electricity/2018/.

—. 2019. "2019 Annual Technology Baseline”. Golden, CO: National Renewable Energy Laboratory. https://atb.nrel.gov/electricity/2019/.

Palchak, David, Jaquelin Cochran, Ali Ehlen, Brendan McBennett, Michael Milligan, Ilya Chernyakhovskiy, Ranjit Deshmukh, et al. 2017. Greening the Grid: Pathways to Integrate 175 Gigawatts of Renewable Energy into India's Electric Grid, Vol. I: National Study. Golden, CO: National Renewable Energy Laboratory. NREL/TP-6A20-68530. http://www.nrel.gov/docs/fy17osti/68530.pdf.

Press Trust of India. 2019. "PM Modi Vows to More than Double India's Non-Fossil Fuel Target to 450 GW." India Today September 24, 2019. https://www.indiatoday.in/india/story/pm-modivows-more-double-india-non-fossil-fuel-target-450-gw-1602422-2019-09-24.

Railway Board. March-2017. Monthly Revenue Freight Track Statistics. New Delhi: Ministry of Railways.

UNFCCC (United Nations United Nations Framework Convention on Climate Change). 2015. India's Intended National Determined Contribution: Working Towards Climate Justice. https://www4.unfecc.int/sites/ndcstaging/PublishedDocuments/India\%20First/INDIA\%20INDC \%20TO\%20UNFCCC.pdf. 